\author{
Report No. BMI-1396 \\ UC-81 Reactors - Power \\ (TID-4500, 15th Ed.)
}

Contract No. W-7405-eng -92

ML-1-1A CORE STUDIES WITH THE GCRE CRITICAL ASSEMBLY

by

Richard A. Egen

William S. Hogan

David A. Dingee

Joel W. Chastain

November 27,1959

BATTELLE MEMORIAL INSTITUTE

$505 \mathrm{King}$ Avenue

Columbus 1, Ohio 


\section{DISCLAIMER}

This report was prepared as an account of work sponsored by an agency of the United States Government. Neither the United States Government nor any agency Thereof, nor any of their employees, makes any warranty, express or implied, or assumes any legal liability or responsibility for the accuracy, completeness, or usefulness of any information, apparatus, product, or process disclosed, or represents that its use would not infringe privately owned rights. Reference herein to any specific commercial product, process, or service by trade name, trademark, manufacturer, or otherwise does not necessarily constitute or imply its endorsement, recommendation, or favoring by the United States Government or any agency thereof. The views and opinions of authors expressed herein do not necessarily state or reflect those of the United States Government or any agency thereof. 


\section{DISCLAIMER}

Portions of this document may be illegible in electronic image products. Images are produced from the best available original document. 


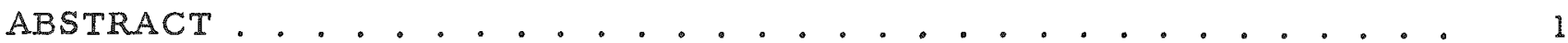

INTRODUCTION . . . . . . . . . . . . . . . . . . . . . 1

DESCRIPTION OF THE ML-1-1A CRITICAL ASSEMBLY . . . . . . . . . . 2

Core Structure and Fuel-Element Lattice . . . . . . . . . . . . 2

Fuel-Element Construction . . . . . . . . . . . . . . 5

RESULTS OF EXPERIMENTS WITH THE ML-1-1A CRITICAL ASSEMBLY . . . 5

Critical Core Configuration . . . . . . . . . . . . . . . 5

Reactivity Worth of Peripheral Fuel Elements . . . . . . . . . . 7

Power-Distribution Measurements . . . . . . . . . . . . . . 8

Flux-Distribution Measurements . . . . . . . . . . . . . 10

Intracell Flux Measurements . . . . . . . . . . . . . . 13

Temperature Coefficient of Reactivity . . . . . . . . . . . 13

Void Coefficients of Reactivity . . . . . . . . . . . . . . 20

Reactivity Worth of ML-1-1A Mock-Up Control-Blade Assembly. . . . . 22

FUEL-ELEMENT-REPLACEMENT STUDIES . . . . . . . . . . . . . . 22

lA Fuel-Element Studies . . . . . . . . . . . . . . 22

GCRE-1B-1фT Fuel-Element Studies . . . . . . . . . . . . 27

Power-Distribution Measurements . . . . . . . . . . . 27

Flux Measurements . . . . . . . . . . . . . . 29

DISCUSSION . . . . . . . . . . . . . . . . . . . . 31

Critical Configuration. . . . . . . . . . . . . . . . . 31

Results of Elux and Power Measurements . . . . . . . . . . . . 31

Reactivity Worth of ML-1-1A Mock-Up Control-Blade Assembly. . . . . 31

Void Coefficient of Reactivity . . . . . . . . . . . . . . . 32

1 A Fuel-Element Studies . . . . . . . . . . . . . . 32

1B Fuel-Element Studies . . . . . . . . . . . . . . 32

REFERENCES . . . . . . . . . . . . . . . . . . . 33 


\title{
ML-1-1A CORE STUDIES WITH THE GCRE CRITICAL ASSEMBLY
}

\author{
Richard A. Egen, William S. Hogan, David A. Dingee, \\ and Joel W. Chastain
}

\begin{abstract}
Critical-assembly studies were conducted to provide physics and engineering data to aid in developing the Mobile Low-Power Reactor (IIL-1).

The ML-1-1A core u'as critical with 59 elements containing $17,906.71 \mathrm{~g}$ of uranium-235, and had an excess reactivity of $0.381 \times 10^{-2} \Delta k / k$ at a moderator temperature of $24.91 \mathrm{C}$. The ratio of maximum element power to core-averaged power was approximately 1.09. The ratio of maximum to core-averaged thermal flux was approximately 1.10. At an 18-deg separation, the shutdown worth of the cadmium-covered control-blade mock-up was $1.14 \times 10^{-2} \Delta k / k$ for a 69-element core. Radial and upper axial reflector-moderator void coefficients were $-0.59 \pm 0.07$ and $-0.366 \pm 0.015 x$ $10^{-2} \Delta k / k$ per in., respectively.

Two $1 \mathrm{~A}$ production fuel elements were evaluated in the critical-assembly core. The results predict that the production elements tested contained roughly the same fuel as the critical-assembly element and an additional $772 \mathrm{~g}$ of stainless steel equivalent on the average. Radial power and neutron-flux distributions were measured in a 19-pin $1 B$ fuel element. Fairly uniform distributions were observed. Data to evaluate the thermal utilization of this element were obtained.
\end{abstract}

\section{INTRODUCTION}

Aerojet-General Nucleonics is developing a transportable gas-cooled nuclear power plant for the Army Reactors Branch of the Atomic Energy Commission. To aid in this development a continuing series of critical-assembly experiments has been in progress at Battelle's Nuclear Research Center for the past 2 years.

The developmental program includes the operation of a gas-cooled watermoderated test-reactor facility, the Gas Cooled Reactor Experiment (GCRE), at the National Reactor Testing Station in Idaho. The initial group of critical-assembly studies was conducted to provide engineering and physics data for the construction of the GCRE. Several core configurations were studied leading to a core for the GCRE which will have sufficient excess reactivity to meet power, lifetime, and operating requirements but which can be adequately shut down when the coolant regions are flooded during fuel-element removal. This initial series of experiments is summarized in BMI-1288. (1)

A second group of studies was undertaken to provide information for evaluating specific design problems and to aid in optimizing and developing advanced concepts of the GCRE. During these studies the Uniform Radial Power Distribution Core (URPD) was investigated. This core departed from the uniform fuel-element spacing of preceding cores; a nonuniform lattice space was designed to give a more uniform radial power distribution. The results of this second group of studies are reported in BMI1306. (2)

(1) References at end of report. 
After concluding the studies pertaining to the GCRE, a series of experiments was undertaken to provide physics and engineering information on the Mobile Low-Power Reactor (ML-1) a prototype of the portable Army Gas-Cooled Reactor. Originally, the ML-1 reactor design incorporated 1 A fuel elements arranged in a nonuniform fuelelement spacing (similar to that used in the URPD core studied earlier). Designs subsequent to the experiments reported herein incorporate a reduced core length and use uranium oxide pins. The se changes were required to significantly reduce the weight of reactor plus shield. The $1 \mathrm{~A}$ fuel element is described in the next section.

In the ML-1-1A studies (a designation to differentiate these studies from later studies using oxide pins, designated ML-1-1B), flux and power distributions were measured, a mock-up scissor-acting control-blade assembly was calibrated, and the reactivity effects of voids at reflector-moderator interfaces were investigated.

In addition, fuel-element-replacement studies were conducted to evaluate production LA fuel elements and to measure neutron-flux and power distribution in a $1 \mathrm{~B}$ element (oxide pin cluster).

\section{DESCRIPTION OF THE ML-1-1A CRITICAL ASSEMB LY}

The main features of the critical-assembly facility are shown in Figure 1. The stand, controls, and other details are fully described in BMI-1288. (1) Several modifications to the core were required for the present research.

\section{Core Structure and Fuel-Element Lattice}

The construction and location of the radial and upper axial reflectors of the ML1-1A critical-as sembly core differed from those of the cores previously studied. The upper axial reflector was steel, 3-1/2 in. thick, fabricated from a 1/2-in. -thick fuelelement positioning plate and two 1-1/2-in. -thick filler plates. Changes were made in several structural components to facilitate removal and to assure accurate repositioning of the entire reflector assembly.

The radial reflector was a regular hexagon $4 \mathrm{in}$. thick and $28 \mathrm{in.}$ long formed of refined lead. It was located $1 / 2$ in. from the nearest fuel element. A 1 -in. gap was provided in one sector for inserting the ML-1-1A mock-up control blade assembly into the core.

The core was constructed so that the bottom of the upper axial reflector was coplanar with the top of the fuel, the top of the lead reflector, and the full-water-height position. The fuel region is $28 \mathrm{in}$. long and begins $4-1 / 2 \mathrm{in}$. above the bottom aluminum positioning and support plates, i.e., there is a 4-1/2-in. bottom water reflector.

The ML-1-1A core structure provided space for 61 fuel elements. Figure 2 shows a sketch of the core plan and tabulates the fuel-element spacings for a symmetry sector. No critical-assembly control rods were located in the ML-1-1A control-blade test sector. 


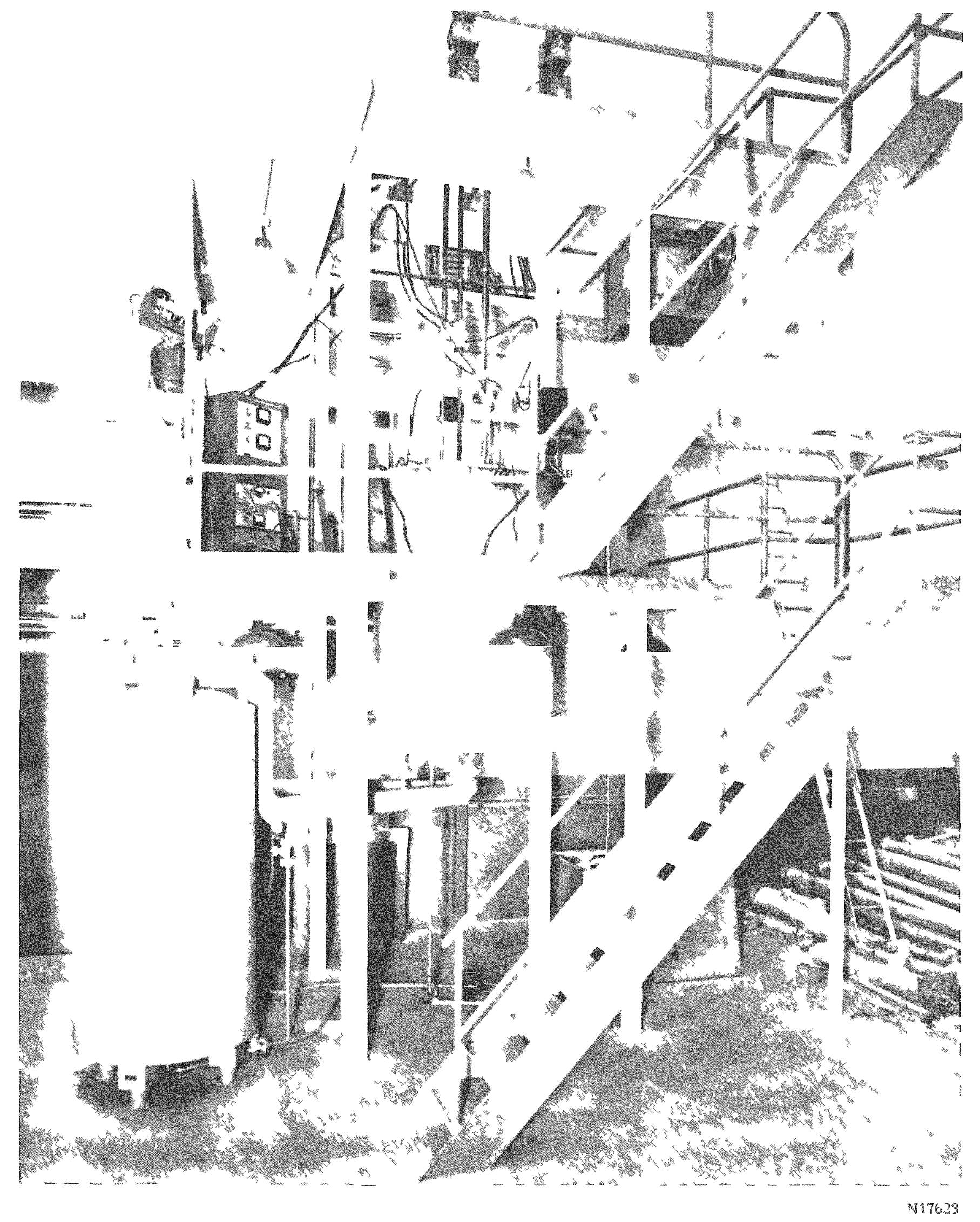

FIGURE 1. GCRE CRITICAL ASSEMBLY 


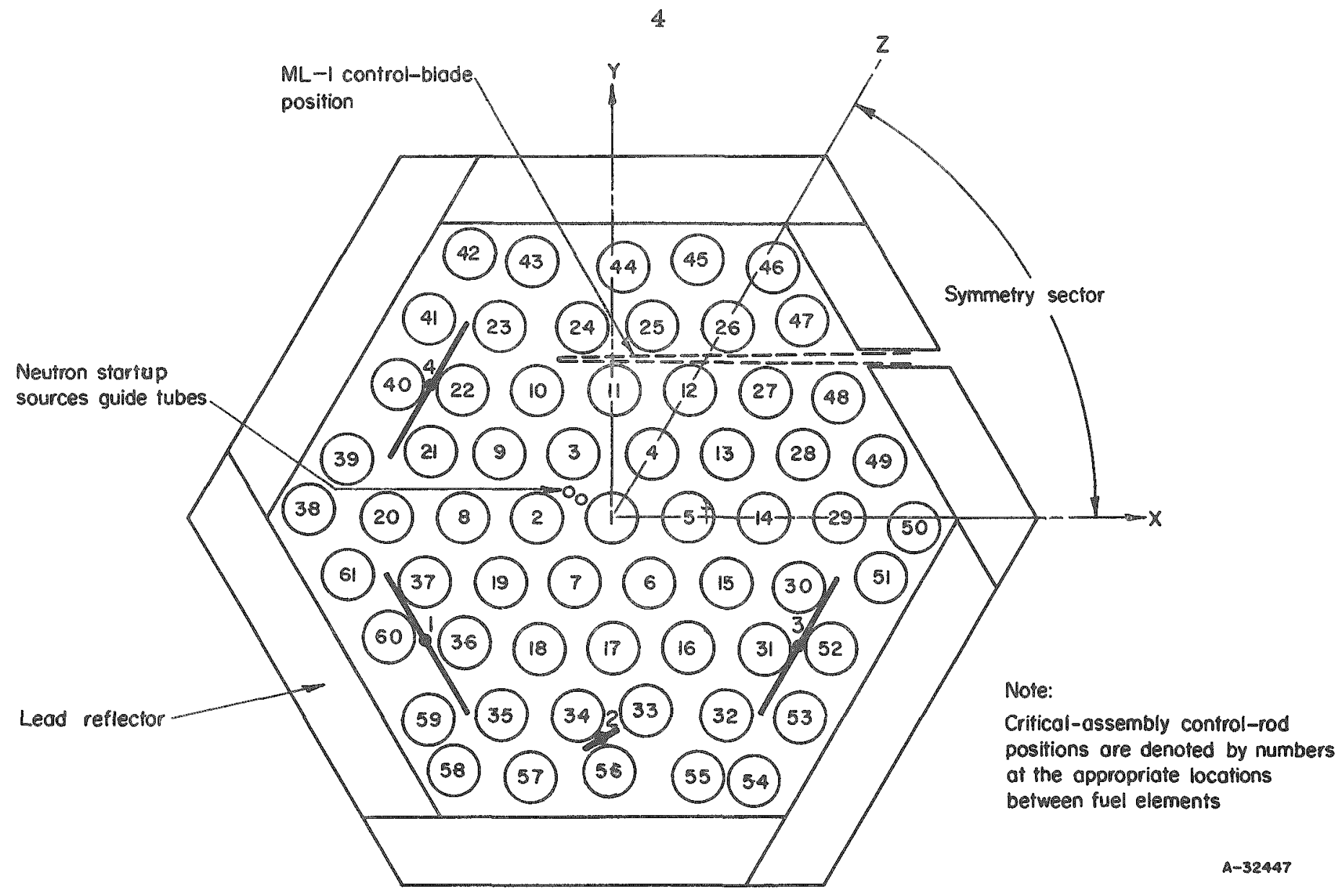

\section{X - Y COORDINATES FOR SYMMETRY SECTOR}

\begin{tabular}{|c|c|c|c|c|c|}
\hline \multirow[b]{2}{*}{ Element Position } & \multicolumn{2}{|c|}{ Coordinate } & \multirow[b]{2}{*}{ Element Position } & \multicolumn{2}{|c|}{ Coordinate } \\
\hline & $\mathrm{X}$, in. & $\mathrm{Y}, \mathrm{in}$. & & $x_{2}$ in. & $\underline{Y, \text { in. }}$ \\
\hline $\mathbb{1}$ & 0 & 0 & 28 & 6.158 & 2.06 \\
\hline 5 & 2.375 & 0 & 49 & 9.095 & 1.955 \\
\hline 14 & 4.75 & 0 & 12 & 2.375 & 4.12 \\
\hline 29 & 7.388 & 0.025 & 27 & 4.999 & 4.07 \\
\hline 50 & 10.173 & -0.299 & 48 & 7.845 & 3.97 \\
\hline 4 & 1. 188 & 2.06 & 26 & 3.673 & 6.415 \\
\hline 13 & 3.563 & 2.06 & 47 & 6.548 & 6.515 \\
\hline & & & 46 & 5.345 & 8.660 \\
\hline
\end{tabular}

FIGURE 2. FUEL-ELEMENT LATTICE SPACING FOR THE ML-1-1A CORE 


\section{Fuel-Element Construction}

The fuel-element assembly is shown in Figure 3. Except for the pressure tube it is identical to that used in previous cores. The stainless steel pressure tube replaced a $0.058 \mathrm{~min}$. -wall aluminum tube $1.875 \mathrm{in}$. in $O D$.

Burnable poison in the core was simulated with a 5-in. -wide band of cadmiumplated steel foil $(0.00012 \mathrm{in}$. of cadmium on 0.015 -in. -thick mild steel) wrapped around the insulation liner of each fuel element and centered $15 \mathrm{in}$. above the bottom of the fuel.

In rewrapping the fuel cylinders for these studies, the enriched-uranium foils (0.00l in. thick, three layers per cylinder) were selected to minimize fuel-loading variations. The average fuel weight per element was $303.40 \mathrm{~g}$ with a maximum deviation of $2.01 \mathrm{~g}$ and a mean deviation of $0.7 \mathrm{~g}$ from this weight.

RESULTS OF EXPERIMENTS WITH THE ML-1-1A CRITICAL ASSEMBLY

The general procedures used in the se studies to determine critical fuel loadings, reactivity effects, flux and power distributions, and thermal utilization are the same as those described in BMI-1288. (1) Procedures applicable to experiments peculiar to this study are discussed in the following sections if they differ from the general procedures.

Experiments with the ML-1-1A critical-assembly core were conducted to determine certain characteristics of the ML-1-1A core:

(1) Critical fuel loading

(2) Flux and power distributions

(3) Reactivity worth of ML-1-1.A mock-up control-blade assembly

(4) Void coefficient of reactivity for voids at the moderator-reflector interfaces.

Reactivity worths were determined either with calibrated critical-assembly control rods or by measured reactor periods resulting directly from the experimental change.

\section{Critical Core Configuration}

The ML-1-1A core was critical with 59 fuel elements arranged as shown in Figure 4. The core contained $17,906.71 \mathrm{~g}$ of uranium-235 and had an excess reactivity of $0.381 \times 10^{-2} \Delta \mathrm{k} / \mathrm{k}$ at a moderator temperature of $24.91 \mathrm{C}$. 


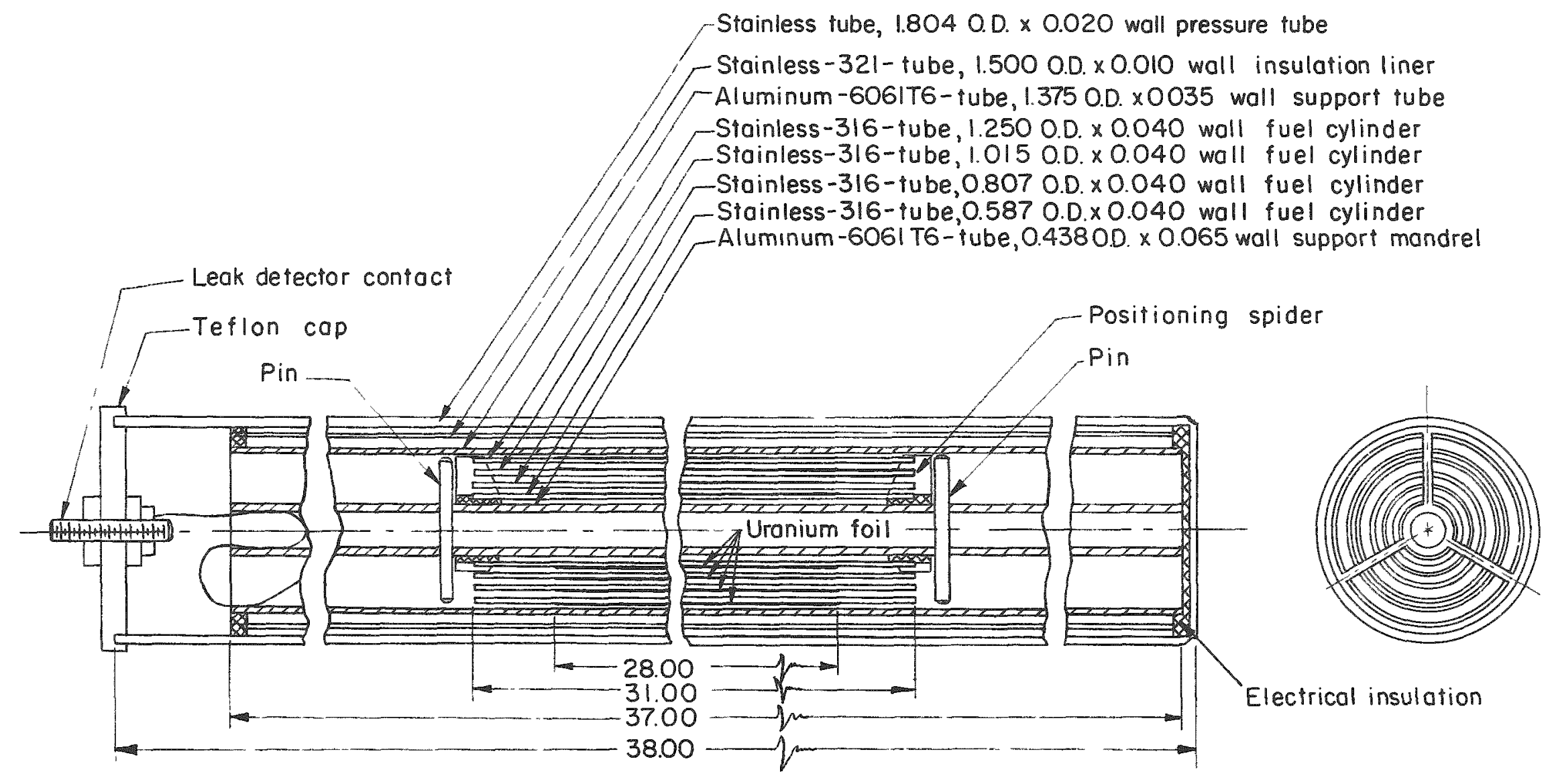

FIGURE 3. FUEL-ELEMENT ASSEMBLY

Burnable poison is not shown.

All dimensions are in inches. 


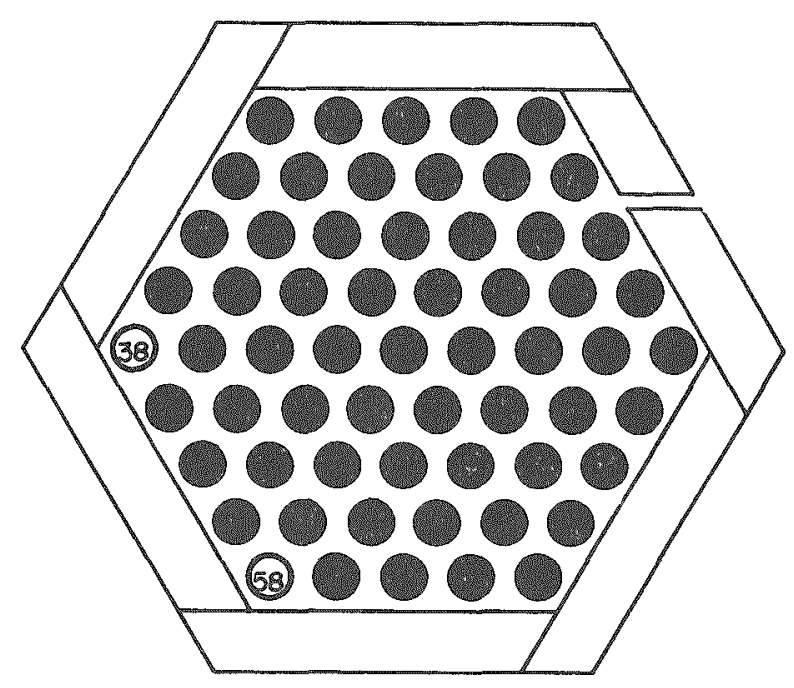

$A-32444$

\section{FIGURE 4. INITIAL CRITICAL CONFIGURATION OF THE ML-1-1A CORE WITH 59 ELEMENTS}

\section{Reactivity Worth of Peripheral Fuel Elements}

Fuel elements were added to two symmetrical core positions, 58 and 38 (see Figure 4), resulting in 60-and 61 -element cores. The excess reactivities associated with the addition of these elements are summarized in Table 1 . The se elements appear to have different worths (corrected to $24.91 \mathrm{C}$ ) $0.44 \times 10^{-2} \Delta \mathrm{k} / \mathrm{k}$ for the element in Position 58 and $0.48 \times 10^{-2} \Delta \mathrm{k} / \mathrm{k}$ for the element in Position 38. This difference is believed to result from incomplete control-rod data for the 59-element and 60-element core arrangements. It was found, for example, that the worth of Rod 2 increased by about 20 per cent when a fuel element was added to Position 58. Rod 4 increased in worth by about 10 per cent when Position 38 was filled. (Note the relative positions of Rods 2 and 4 and Positions 38 and 58 in Figure 2.) For the 60-element core the Rod 4 calibration for the 59-element core and the Rod 2 calibration for the 61 -element core were used.

TABLE 1. WORTH OF PERIPHERAL ELEMENTS IN THE ML-1-1A CORE

\begin{tabular}{|c|c|c|c|}
\hline $\begin{array}{c}\text { Number of } \\
\text { Fuel Elements }\end{array}$ & $\begin{array}{c}\text { Fuel } \\
\text { Inventory, } \\
\mathrm{g} \\
\end{array}$ & $\begin{array}{c}\text { Excess Reactivity } \\
\text { per cen } \Delta \mathrm{k} / \mathrm{k}\end{array}$ & $\begin{array}{c}\text { Worth per Element, } \\
\text { per cent } \Delta \mathrm{k} / \mathrm{k}\end{array}$ \\
\hline 59 & $17,906.71$ & 0.381 at $24.91 \mathrm{C}$ & $\infty$ \\
\hline $\begin{array}{l}60 \text { (element added to } \\
\text { Position 58) }\end{array}$ & $18,208.56$ & $\begin{array}{l}0.824 \text { at } 25.33 \mathrm{C} \\
\text { or } 0.820 \text { corrected to } \\
2 \pm .91 \mathrm{C}\end{array}$ & 0.44 \\
\hline $\begin{array}{l}\text { 1. (elements added to } \\
\text { Posicions } 38 \text { and } 58 \text { ) }\end{array}$ & 18.510 .90 & $\begin{array}{l}1.339 \text { at } 28.45 \mathrm{C} \\
\text { o: } 1.305 \text { corrected to } \\
24.91 \mathrm{C}\end{array}$ & 0.48 \\
\hline
\end{tabular}


Power-Distribution Measurements

With the core in the initial critical configuration (Figure 4) relative power distributions were measured in each fuel element in the symmetry sector defined by the triangle joining Positions 1, 42, and 46 (see Figure 2).

Aluminum catcher foils, 1/2 in. wide and $0.001 \mathrm{in.} \mathrm{thick,} \mathrm{were} \mathrm{wrapped} \mathrm{com-}$ pletely around each fuel cylinder of each element, $8 \mathrm{in}$. above the bottom of the fucl. Power distribution was previously measured by attaching 1/2-in.-diameter aluminum catcher foils to diametrically opposite points on the individual fuel cylinders (see BMI-1306). After irradiation the foils were folded to fit under scintillation counters and the fission-product activity of the entire foil was measured. The measured activities are proportional to the total power generated in the cylinder at that position.

The results of the relative-power-distribution measurements are shown in Figure 5. The quantity, $\mathrm{P} / \overline{\mathrm{P}}$, is defined as the ratio of the power developed in a given element to the core-averaged (radially) power as determined from measurements in a symmetry sector. The core-averaged power is defined as:

$$
\bar{p}=\frac{\sum_{i} \sum_{j} P_{i j} N_{i}}{N},
$$

where

$N_{i}=$ the number of elements of type $i$ in the core

$N=\sum_{i} N_{i}=$ total number of elements in core

$P_{i j}=$ measured catcher-foil activity on the $j$ th fuel cylinder in the ith element.

The data of Figure 5 do not indicate any consistent preferred variation of $P / \bar{P}$ with position except in a radial direction. Nonuniformity of foils and cleanliness of the adjacent fuel are felt to be the principal causes of scatter in the data. Asymmetry of the 59-element core may also contribute to apparent asymmetry of the power distribution.

The maximum ratios of local power to core-averaged power occur where the lattice spacing changes from a uniform hexagon (Positions 1 through 19) to a nonuniform one, i.e., at Positions 8 through 19. For comparison the corresponding data from the URPD core are also shown on Figure 5. These values were obtained by averaging the relative power from the two points (mentioned above) on each fuel cylinder and are, therefore, only approximate.

Table 2 lists the relative total power generated in each element of the sector and the percentage of the total power generated in each fuel cylinder. The data indicate that, in general, the percentage of total power generated in the outer cylinder increases with increasing radius, and that generated in the inner cylinder decreases with increasing radius. 


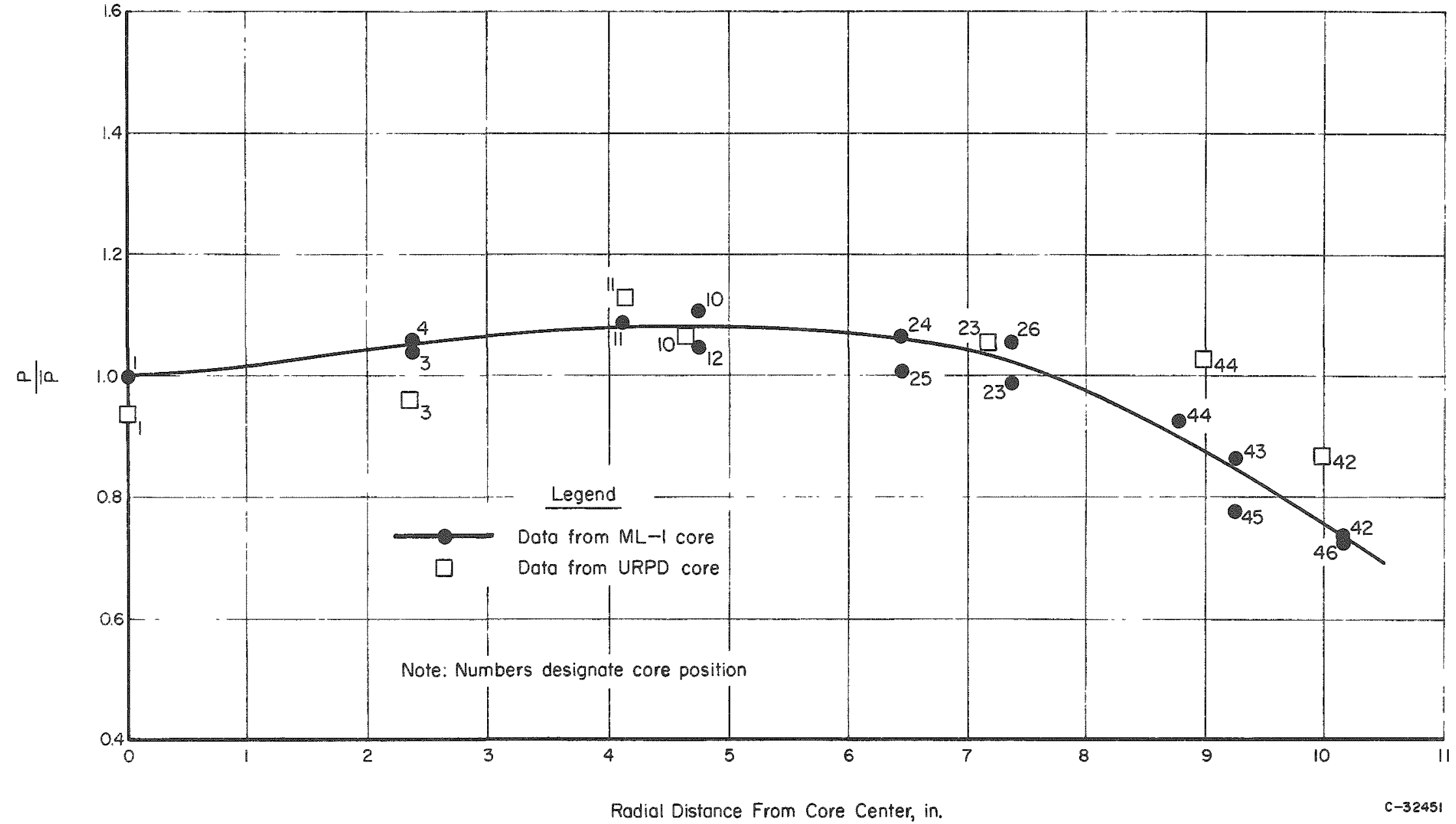

FIGURE 5. RADIAL POWER DISTRIBUTION IN THE ML-1-IA CORE

Data were obtained with aluminum catcher foil around each fuel cylinder on the elements in the indicated core positions. 
TABLE 2. PER CENT TOTAL ELEMENT POWER GENERATED IN EACH FUEL CYLINDER

\begin{tabular}{|c|c|c|c|c|c|c|}
\hline \multirow[b]{2}{*}{$\begin{array}{c}\text { Fuel-Element } \\
\text { Position }\end{array}$} & \multirow{2}{*}{$\begin{array}{c}\text { Radial Distance } \\
\text { From Core Center, } \\
\text { in. }\end{array}$} & \multicolumn{4}{|c|}{$\begin{array}{c}\text { Per Cent Total Power Generated } \\
\text { in Fuel Cylinder Indicated }\end{array}$} & \multirow[b]{2}{*}{$\begin{array}{l}\text { Relative Total } \\
\text { Power }\end{array}$} \\
\hline & & $\begin{array}{c}1 \\
\text { (Inner) }\end{array}$ & 2 & 3 & $\begin{array}{c}4 \\
\text { (Outer) }\end{array}$ & \\
\hline 1 & 0 & 11.50 & 18.10 & 27.20 & 43.20 & 1.00 \\
\hline 3 & 2.37 & 11.45 & 17.10 & 27.60 & 43.85 & 1.04 \\
\hline 4 & 2.37 & 11.50 & 17.55 & 26.00 & 44.95 & 1.06 \\
\hline 10 & 4.75 & 11.00 & 16.95 & 27.10 & 45.00 & 1.11 \\
\hline 11 & 4.12 & 11.80 & 17.30 & 27.55 & 43.60 & 1.09 \\
\hline 12 & 4.75 & 11.65 & 17.30 & 25.75 & 45.30 & 1.05 \\
\hline 23 & 7.39 & 10.95 & 17.85 & 26.70 & 44.50 & 0.99 \\
\hline 24 & 6.45 & 11.15 & 17.10 & 25.85 & 45.95 & 1.07 \\
\hline 25 & 6.49 & 11. 20 & 17.10 & 27.55 & 44.20 & 1.01 \\
\hline 26 & 7.39 & 11.00 & 16.65 & 27.70 & 44.65 & 1.06 \\
\hline 42 & 10.18 & 10.00 & 17.40 & 25.85 & 46.70 & 0.74 \\
\hline 43 & 9.24 & 11.20 & 16.55 & 26.80 & 45.50 & 0.87 \\
\hline 44 & 8.79 & 10.90 & 15.90 & 25.15 & 48.05 & 0.93 \\
\hline 45 & 9.30 & 12.00 & 16.00 & 26.30 & 45.70 & 0.78 \\
\hline 46 & 10.18 & 10.65 & 17.05 & 25.35 & 46.25 & 0.73 \\
\hline
\end{tabular}

\section{Flux-Distribution Measurements}

Axial and radial relative-flux distributions were measured in the 59-element core with bare and cadmium-covered manganese-iron wires located in the center mandrels of fuel elements within the symmetry sector defined by the triangle through Positions 1 , 42, and 46. Axial distributions were obtained in Positions 1 and 26. Radial-distribution data were taken 8 in. above the bottom of the fuel in all positions.

Radial-flux data are shown in Figure 6. The quantity $A / \overline{\mathrm{A}}_{\mathrm{T}}$ is defined to be the ratio of the local wire activity (either bare or cadmium covered) to the core-averaged (radially) value of the bare-wire activities measured in the center mandrels.

For comparison the corresponding data from the URPD core are also presented. The URPD data measured along two core radii show a peak in the total flux distribution. The data from the ML-1-1A core indicate a small radial variation of flux but no peak. The data also indicate that the ML-1-1A core configuration reduces the ratio of maximum to average flux in the center mandrel from 1.21 in the URPD core to 1.17.

The axial-flux-distribution data are presented in Figure 7. The corresponding data from Position 1 of the URPD core are included. The latter data are normalized to the former on the basis of equal integrals under the curves shown. The higher values in the ML-1-1A core toward the top of the fuel element may be attributed to the steel reflector (aluminum in the URPD core). 


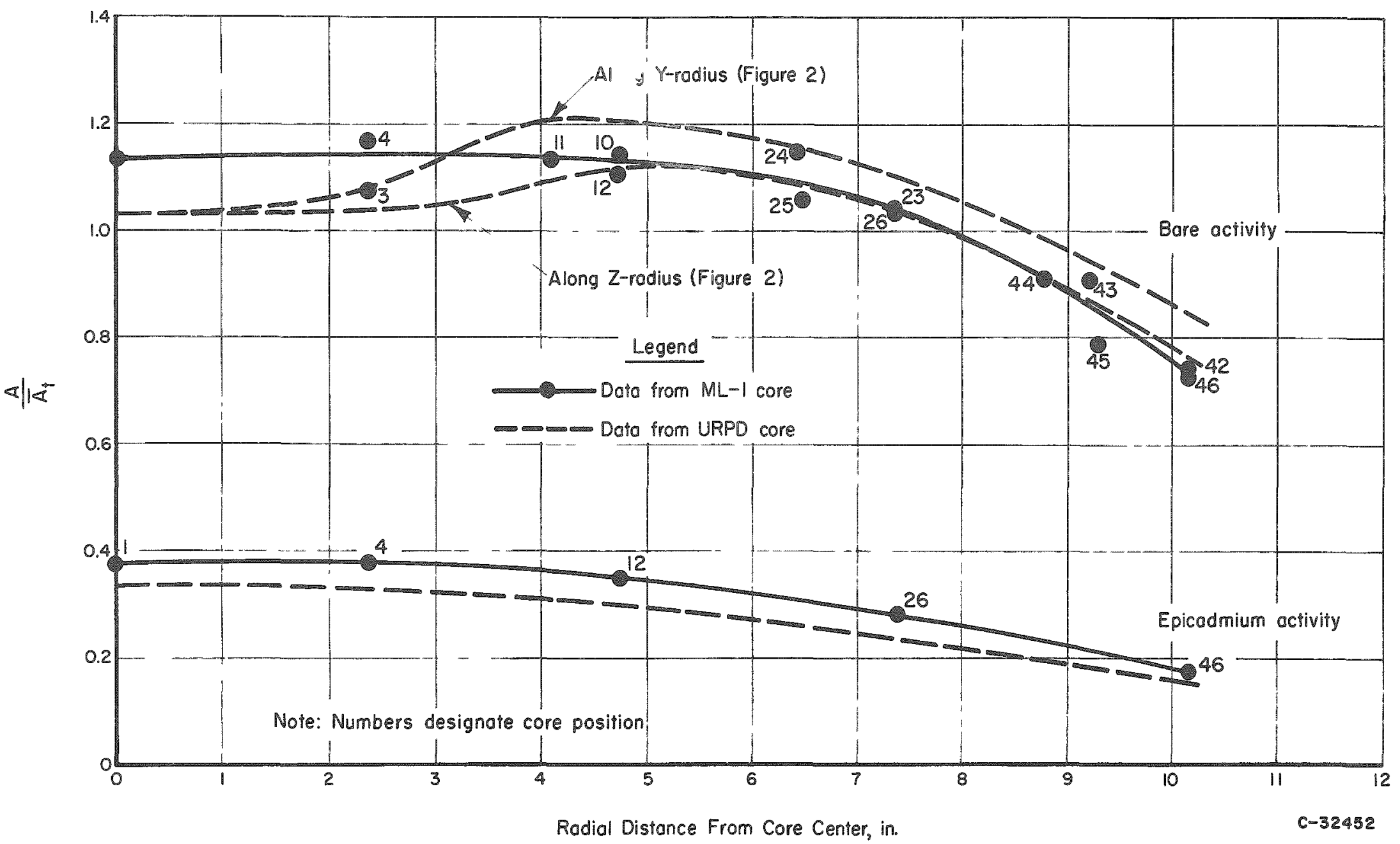

FIGURE 6. RADIAL-FLUX-DISTRIBUTION DATA IN ML-1-IA CORE

Data were obtained using manganese-iron wires at the center of fuel elements in indicated core positions. 


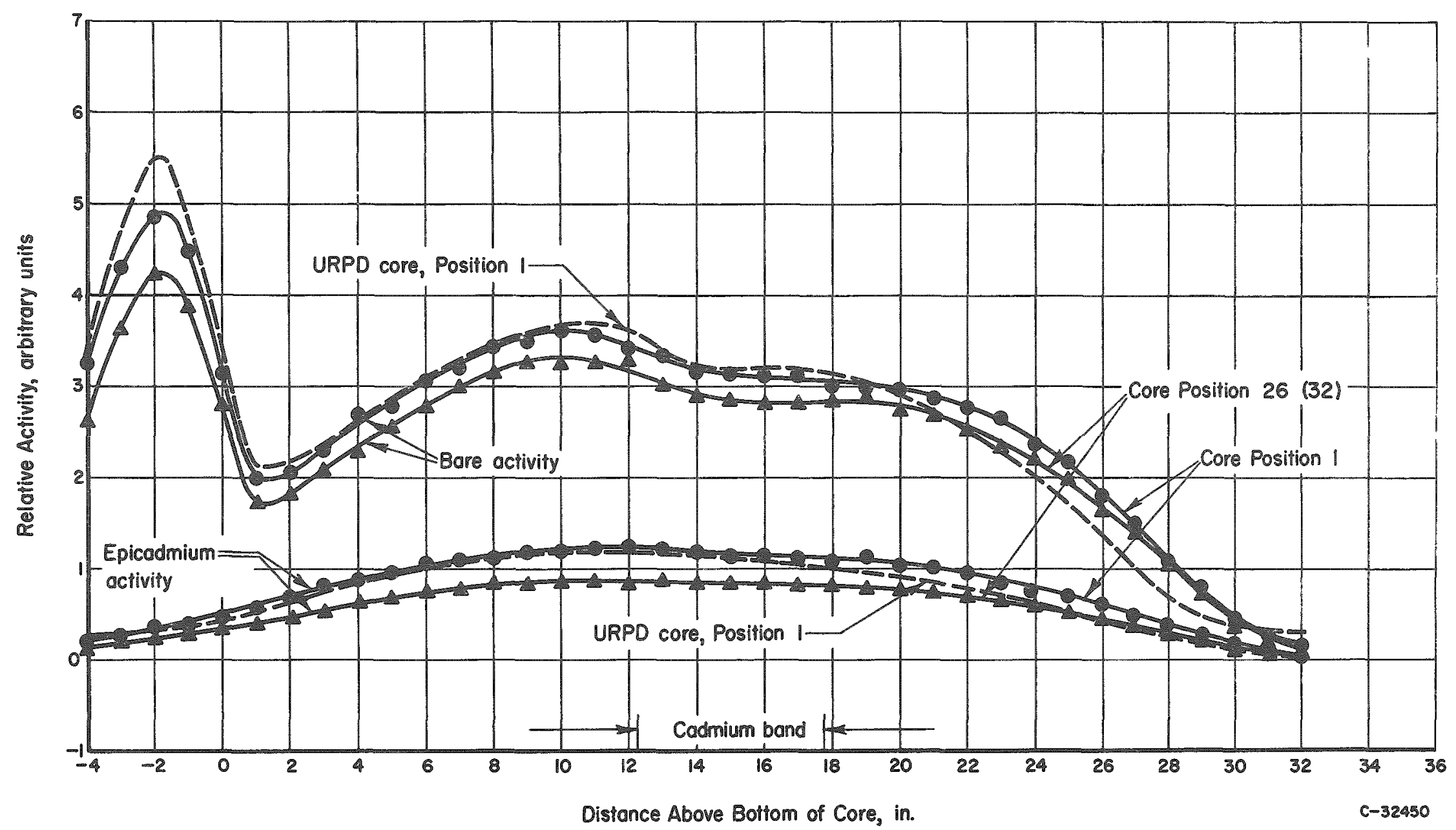

FIGURE 7. AXIAL-FLUX-DISTRIBUTION DATA FOR THE ML-1-1A CORE

Data were obtaned using mangantatiron wires at the center of $f$ el elenterts in the nudicated core positions. 
Intracell Flux Measurements

Detailed flux measurements were made within and around the fuel elements in Positions 1, 12, 26, and 45 at a point centered 8 in. above the bottom of the fuel. These measurements were made in the 59-element core arrangement shown in Figure 4 using 33-mil-diameter manganese-iron wires.

The relative positions of both the bare and cadmium-covered wires are shown in Figure 8. Wires within the element were taped onto the outside of the indicated cylinders. The moderator wires were held vertically in specially constructed $1 / 2$-in. - thick polyethylene holders. Special tests were performed using p-metal wires (more manganese) to show that the wire absorption does not affect the results significantly. Moderator wires lie on lines joining centers of adjacent elements and on perpendicular bisectors to these lines. In some instances additional wires are positioned to equally subdivide the distance between the fuel-element perimeter and the perpendicular bisector lines. The number of epicadmium measurements was limited by structural restrictions and flux-perturbation considerations.

The background-corrected and normalized data are presented in Table 3. The data from comparable positions in each of the four fuel elements show the same general radial variation as indicated in Figure 6 . It may be noted that wires were activated in nearly identical positions between elements in Positions 12 and 26 and Positions 26 and 45. The normalized activities of the se wires are not in close agreement. This is believed to be a result of small errors in positioning the se wires. A small positioning error can lead to a large difference in activity because of the severe flux peaking in the moderator region. Such positioning errors average out over the large number of measured points and are not believed to affect the determination of the average flux in the moderator.

The data from Table 3 were used in calculating thermal-utilization values. The pertinent parameters and data are listed in Tables 4 and 5. As in previous calculations the flux shape through the fuel plate is not taken into account. That is, surface values, averaged over the perimeter, are assumed to apply through the cylinders where measurements were made. A more extensive analysis of the neutron-absorption process would be required to properly interpret the data. However, it appears that the present method of data reduction demonstrates correctly the variation in core properties between the ML-1-1A and URPD core geometries. Figure 9 shows this comparison. The core-averaged value of thermal utilization for the ML-1-1A core is approximately 0.005 below the URPD core value.

\section{Temperature Coefficient of Reactivity}

In attempting certain measurements, it was found that the reactivity changes which were being measured were small enough to be appreciably affected by moderatortemperature changes. To correct for these changes, the moderator-temperature coefficient was measured for one temperature change. This measurement was made in a 61-element core. The temperature change was just the natural change which occurred during the day, and hence was small $(28.19$ to $28.90 \mathrm{C})$. The value obtained was 

A. Support mandrel
B. Fuel cylinder
C. Fuel cylinder
D. Fuel cylinder
E. Fuel cylinder
F. Insulation liner
G. Pressure tube

H. (Positions $1,12,26$ ) wires that lie midway between $G$ and I

I. (Positions $1,12,26)$ perimeter wires

H. 2. 1. (Position 45 only) wires that lie evenly spaced between

$G$ and $J$

J. (Position 45 only) perimeter wires
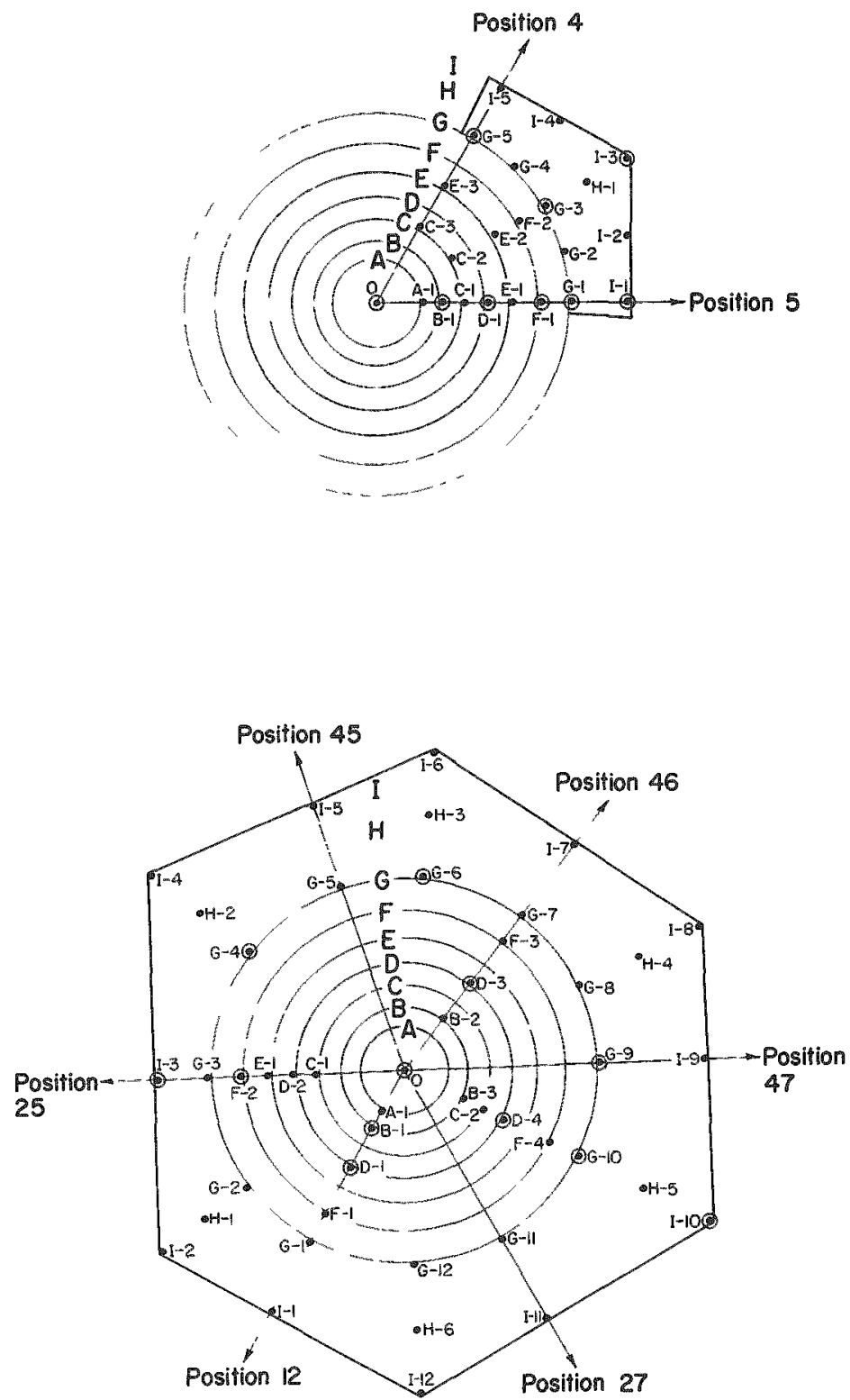

FIGURE $\leadsto$. WIRE POSITIONS FOR FUEL ELEMENTS IN POSITIONS 1, 12, 26. AND 45

Cadminm-covered wires were located at circled points and inradiated separately. Arrow point toward inderted core positions. 

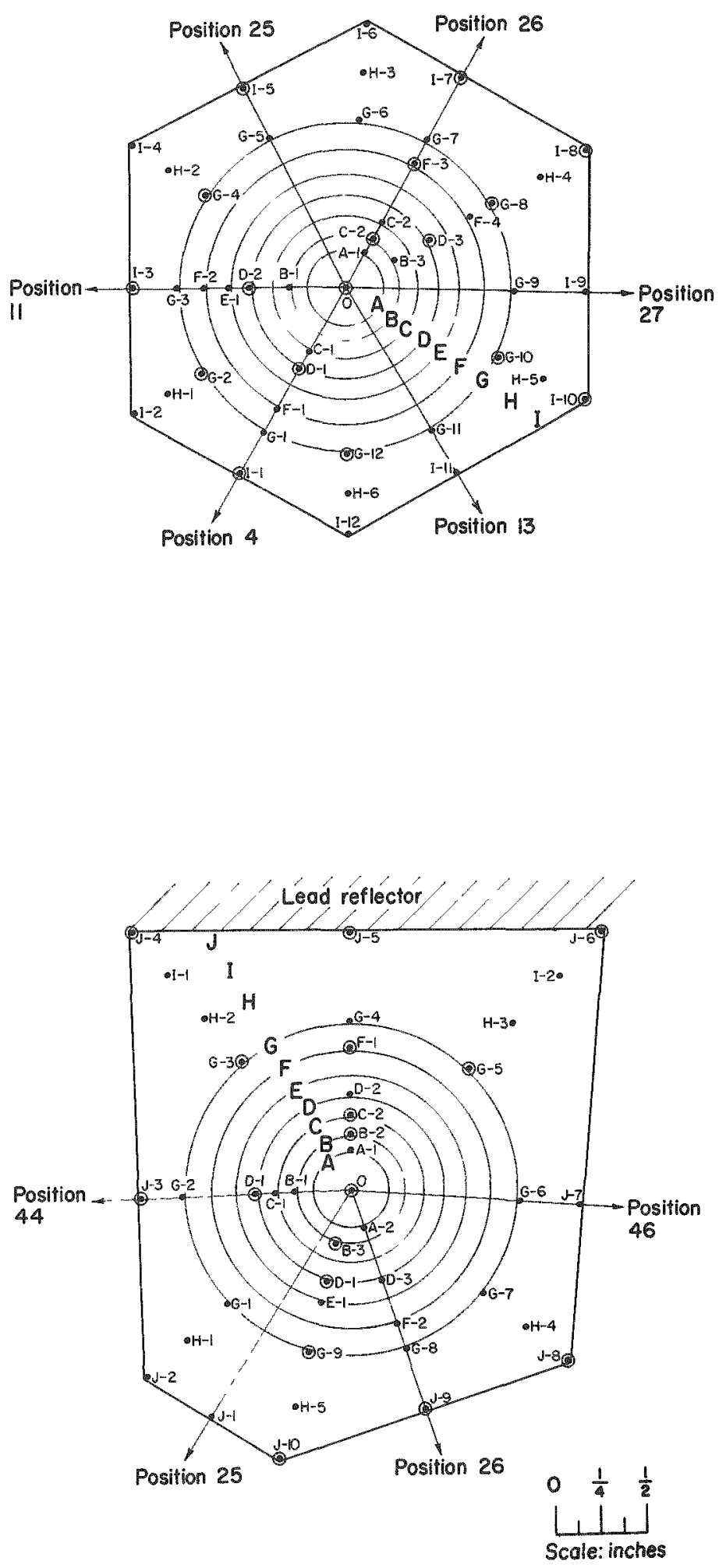

FIGURE 8. (CONTINUED) 
TABLE 3. RELATIVE INTRACELL FLUX-DISTRIBUTION DATA FOM CORE POSITIONS SHOWN IN FIGURE 8

\begin{tabular}{|c|c|c|c|c|c|c|c|c|}
\hline \multirow[b]{3}{*}{$\begin{array}{c}\text { Wire } \\
\text { Position }\end{array}$} & \multicolumn{8}{|c|}{ Relative Normalized Activity Obtained From Position Shown } \\
\hline & \multicolumn{2}{|c|}{ Position 1} & \multicolumn{2}{|c|}{ Position 12} & \multicolumn{2}{|c|}{ Position 26} & \multicolumn{2}{|c|}{ Position 45} \\
\hline & Bare Wire & $\begin{array}{l}\text { Cadmium- } \\
\text { Covereal Wire }\end{array}$ & Bare Wire & $\begin{array}{l}\text { Cadmium- } \\
\text { Covered Wire }\end{array}$ & Bare Wire & $\begin{array}{l}\text { Cadmiun- } \\
\text { Covered Wire }\end{array}$ & Bare Wire & $\begin{array}{l}\text { Cadmium- } \\
\text { Covered Wire }\end{array}$ \\
\hline 0 & 3,440 & 1135 & 3,477 & 1061 & 3,155 & 859 & 2.394 & 619 \\
\hline$A-1$ & 3,351 & $-\infty$ & 3.329 & $-\infty$ & 3,056 & -- & 2,300 & -- \\
\hline 2 & $-\infty$ & - & $-\infty$ & -- & -- & $-\infty$ & 2,362 & - \\
\hline$B-1$ & 3,441 & 1117 & 3,374 & -- & 3,093 & 804 & 2,400 & $\cdots$ \\
\hline 2 & - & $\ldots$ & 3,226 & 944 & 3.174 & $-\infty$ & 2.311 & 616 \\
\hline 3 & -- & -- & 3,468 & - & 3,076 & $=-$ & 2,547 & $\infty$ \\
\hline$C-1$ & 3,798 & -- & 3,684 & $-\infty$ & 3,533 & -- & 2,658 & $-\infty$ \\
\hline 2 & 3,806 & $-\infty$ & 3.877 & $\infty$ & 3,375 & $\infty$ & 2.505 & $-\infty$ \\
\hline 3 & 3,666 & $-\infty$ & -- & $-\infty$ & $-\infty$ & $-\infty$ & $-\infty$ & -- \\
\hline$D-1$ & 4.678 & 1214 & 4.673 & -- & 4,218 & 899 & 3,176 & 648 \\
\hline 2 & - - & $-\infty$ & 4.560 & 1041 & 4,379 & $=-$ & 2,964 & 584 \\
\hline 3 & $-\infty$ & $-\infty$ & 4,842 & 1045 & 4,405 & 818 & 3.413 & $\infty$ \\
\hline 4 & $\infty-$ & $-\infty$ & -- & $\infty$ & 4.412 & 864 & 3,552 & 678 \\
\hline$E-1$ & 6,331 & - & 6,261 & $-\infty$ & 6.479 & $-\infty$ & 5,009 & $-\infty$ \\
\hline 2 & 6,145 & $-\infty$ & $-\infty$ & $=$ & $\infty$ & $-\infty$ & $\omega=$ & on m \\
\hline 3 & 5,954 & $=-$ & -- & $=-$ & - & - & $-\infty$ & - \\
\hline$F-1$ & 7.059 & 1340 & 7,160 & - & 6,425 & -- & 4,731 & 740 \\
\hline 2 & 7.179 & $=-$ & 7,002 & $\infty$ & 7,150 & 971 & 5,632 & $-\infty$ \\
\hline 3 & $=-$ & $-\infty$ & 7,538 & 1163 & 6.564 & $-\infty$ & $=$ & -- \\
\hline 4 & $-\infty$ & -- & 7,546 & $-\infty$ & 6,102 & $\infty$ & $-\infty$ & $-\infty$ \\
\hline$G-1$ & 8,785 & 1433 & 7.931 & $\ldots$ & 7,175 & -- & 6,872 & $-\infty$ \\
\hline 2 & 8,079 & $-\infty$ & 8,369 & 1272 & 7,231 & -- & 6,676 & - \\
\hline 3 & 8.010 & 1435 & 7.964 & $\infty-$ & 6,840 & -- & 5,367 & -- \\
\hline 4 & 8,116 & $-\infty$ & 8,002 & 1249 & 6,870 & 995 & 5,780 & 752 \\
\hline 5 & 7.634 & 1433 & 8,618 & $-\infty$ & 6,963 & -- & 4.974 & $=-$ \\
\hline 6 & $=$ & -- & 8,654 & $\infty$ & 7,367 & 954 & 5,380 & 622 \\
\hline 7 & 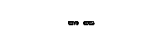 & -- & 8.743 & $=\infty$ & 7,722 & $-\infty$ & 5,372 & $-\infty$ \\
\hline 8 & $-\infty$ & -- & 8.845 & 1135 & 7,771 & 963 & 6,027 & -- \\
\hline 9 & -- & - & 8,604 & $=-$ & 8,023 & - & 6,197 & $-\infty$ \\
\hline 10 & - & -- & 8.450 & 1175 & 8.510 & 980 & 6.882 & 849 \\
\hline 11 & -- & -- & 7.758 & $\infty$ & 7,827 & $=-$ & -- & $-\infty$ \\
\hline 12 & -- & - & 8,356 & 1257 & 7.782 & -- & -- & -- \\
\hline $\mathrm{H}-1$ & 11.926 & $\infty+\infty$ & 12,101 & $-\infty$ & 11,270 & $=-$ & 11.971 & $-\infty$ \\
\hline 2 & $=-$ & $\cdots$ & 12,922 & $=-$ & 10,457 & $\infty$ & 9,158 & -- \\
\hline 3 & - & - & 12,642 & -- & 12,265 & $-\infty$ & 9,221 & -- \\
\hline 4 & - & $-\infty$ & 14,360 & -- & 14,273 & $-\infty$ & 9,642 & $m$ \\
\hline 5 & $\infty$ & $-\infty$ & 12,931 & $-\infty$ & 14,678 & - & 12,204 & $-\infty$ \\
\hline 6 & $-\infty$ & -- & 11,903 & $-\infty$ & 12,638 & $-\infty$ & $-\infty$ & $-\infty$ \\
\hline$I-1$ & 11,115 & 1485 & 11,299 & 1314 & 9,758 & $-\infty$ & 10,164 & - \\
\hline 2 & 11,635 & $-\infty$ & 13,099 & - & 12,264 & -- & 9,857 & - \\
\hline 3 & 12,598 & 1518 & 10,953 & 1328 & 10,345 & 1065 & $-\infty$ & $=-$ \\
\hline 4 & 11,818 & $-\infty$ & 13,969 & - & 10,628 & $-\infty$ & $-\infty$ & -- \\
\hline 5 & 10,752 & $-\infty$ & 12,002 & 1221 & 11,061 & $-\infty$ & - & -- \\
\hline
\end{tabular}


TABLE 3. (Continued)

\begin{tabular}{|c|c|c|c|c|c|c|c|c|}
\hline \multirow[b]{3}{*}{$\begin{array}{c}\text { Wire } \\
\text { Position }\end{array}$} & \multicolumn{8}{|c|}{ Relative Normalized Activity Obtained From Position Shown } \\
\hline & \multicolumn{2}{|c|}{ Position 1} & \multicolumn{2}{|c|}{ Position 12} & \multicolumn{2}{|c|}{ Position 20} & \multicolumn{2}{|c|}{ Position 45} \\
\hline & Bare Wire & $\begin{array}{l}\text { Cadmium- } \\
\text { Covered Wire }\end{array}$ & Bare Wire & $\begin{array}{c}\text { Cadmium } \\
\text { Covered Wire }\end{array}$ & Bare Wire & $\begin{array}{c}\text { Cadmium- } \\
\text { Covared Wire }\end{array}$ & Bare Wire & $\begin{array}{l}\text { Cadmium- } \\
\text { Covared Wure }\end{array}$ \\
\hline$I=6$ & $-\infty$ & $=-$ & 13,672 & $\ldots$ & 11,981 & $\ldots$ & $-\infty$ & - \\
\hline 7 & $-\infty$ & -- & 13,748 & 1207 & 14,226 & 841 & $-=$ & $-\infty$ \\
\hline 8 & -- & - & 15,769 & 1249 & 15,918 & $-\infty$ & $\infty$ & $\infty$ \\
\hline 9 & $-\infty$ & $-\infty$ & 13,229 & $-\infty$ & 13,805 & $-\infty$ & $-\infty$ & -- \\
\hline 10 & $-\infty$ & $\infty$ & 14,006 & 1353 & 15.640 & 1038 & - & $-\infty$ \\
\hline 11 & -- & -- & 11,072 & $-\infty$ & 14,139 & - & $-\infty$ & $\ldots$ \\
\hline 12 & - & $\infty$ & 13,108 & -- & 13,809 & -- & $\ldots$ & -- \\
\hline$J-1$ & $\ldots$ & -- & $-\infty$ & $-\infty$ & $\infty$ & $-\infty$ & $13_{2} 407$ & -- \\
\hline 2 & $-m$ & $-\infty$ & - & $-\infty$ & $\infty$ & -- & 13,010 & -- \\
\hline 3 & $\ldots$ & $-\infty$ & $-\infty$ & $-\infty$ & -- & $-\infty$ & 7.725 & 810 \\
\hline 4 & - & $-\infty$ & $-\infty$ & $-\infty$ & $-\infty$ & $-\infty$ & 9,149 & 662 \\
\hline 5 & - & $\infty$ & $-\infty$ & - & -- & -- & 7.732 & 634 \\
\hline 6 & $-\infty$ & $=-$ & $-\infty$ & $\infty$ & -- & $-\infty$ & 8,280 & 601 \\
\hline 7 & $=$ & -- & $-\infty$ & -- & $-\infty$ & $-\infty$ & 7.734 & $-\infty$ \\
\hline 8 & $\ldots$ & $\infty$ & $=$ & - & -- & $-\infty$ & 10.719 & 846 \\
\hline 9 & $-\infty$ & $-\infty$ & $-\infty$ & $=$ & $\infty$ & $\infty$ & 10,032 & 898 \\
\hline 10 & $-\infty$ & -- & $-\infty$ & $=$ & -- & $\infty$ & 13,269 & 1017 \\
\hline
\end{tabular}


TABLE 4. PARAMETERS USED IN THERMAL-UT ILIZATION CALCULATIONS

\begin{tabular}{|c|c|c|c|c|}
\hline & Position 1 & Position 12 & Position 26 & Position 45 \\
\hline Cell Area, in. ${ }^{2}$ & 4.834 & 5.257 & 6.005 & 6.513 \\
\hline \multicolumn{5}{|c|}{$\begin{array}{l}\text { Anoune of Indicated Material in } \\
\text { Total Coll Volume, per cent }\end{array}$} \\
\hline Moderator & 47.91 & 52.23 & 58.06 & 60.72 \\
\hline Aluminum & 4.58 & 4.19 & 3.68 & 3.45 \\
\hline Stanless Steel & 12.26 & 11.24 & 9.87 & 9.24 \\
\hline Uranimum-235 & 0.78 & 0.72 & 0.63 & 0.58 \\
\hline \multicolumn{5}{|c|}{$\begin{array}{l}\text { Ratio of Material Volume to } \\
\text { Fuel Yolume }\end{array}$} \\
\hline Moderator & 61.23 & 72.66 & 92.41 & 102.93 \\
\hline Aluminum & 5.85 & 5.76 & 5.87 & 5.85 \\
\hline Stainless Steel & 15.67 & 15.63 & 15.71 & 15.67 \\
\hline Uranium-235 & 1.00 & 1.00 & 1.00 & 1.00 \\
\hline Cross-Section Data & $\sigma(a)$, barns & $\Sigma \mathrm{cm}^{-1}$ & \multicolumn{2}{|c|}{ Ratio to Fuel Cross Section } \\
\hline Moderator & 0.539 & 0,0196 & \multicolumn{2}{|c|}{0.000686} \\
\hline Aluminum & 0.204 & 0.123 & \multicolumn{2}{|c|}{0.000431} \\
\hline Stainless Steel & 2.66 & 0.2217 & \multicolumn{2}{|c|}{0.007764} \\
\hline Uranium -235 & $599^{(b)}$ & 28.555 & \multicolumn{2}{|c|}{1.00} \\
\hline
\end{tabular}

(a) Corrected for Maxwellian distribution at $25 \mathrm{C}$.

(b) Corrected for non $-1 / \mathrm{v}$ dependence.

TABLE 5. THERMALUTILIZATION DATA

\begin{tabular}{|c|c|c|c|c|}
\hline & Position 1 & Position 12 & Position 26 & Position 45 \\
\hline \multicolumn{5}{|c|}{$\begin{array}{l}\text { Average Relative Themal Flux } \\
\text { in Indicated Material }\end{array}$} \\
\hline Moderator & 8633 & 10302 & 10231 & 8037 \\
\hline Aluminum & 4000 & 4181 & 4160 & 3112 \\
\hline Stainless Steel & 4351 & 4583 & 4368 & 3161 \\
\hline Uranium-235 & 3591 & 3748 & 3669 & 2752 \\
\hline \multicolumn{5}{|c|}{$\begin{array}{l}\text { Rativ of Flux in Material to } \\
\text { Flux in Fuel }\end{array}$} \\
\hline Moderatol & 2.40 & 2.75 & 2.79 & 2.92 \\
\hline Aluminum & 1.11 & 1. 1.2 & 1.13 & 1.13 \\
\hline Stainless Steel & 1.21 & 1.22 & 1.19 & 1.26 \\
\hline Urani um-235 & 1.00 & 1.00 & 1.00 & 1.00 \\
\hline $\begin{array}{l}\text { Calculated Values o } \\
\text { Utilization }\end{array}$ & 0.799 & 0.776 & 0.755 & 0.734 \\
\hline
\end{tabular}




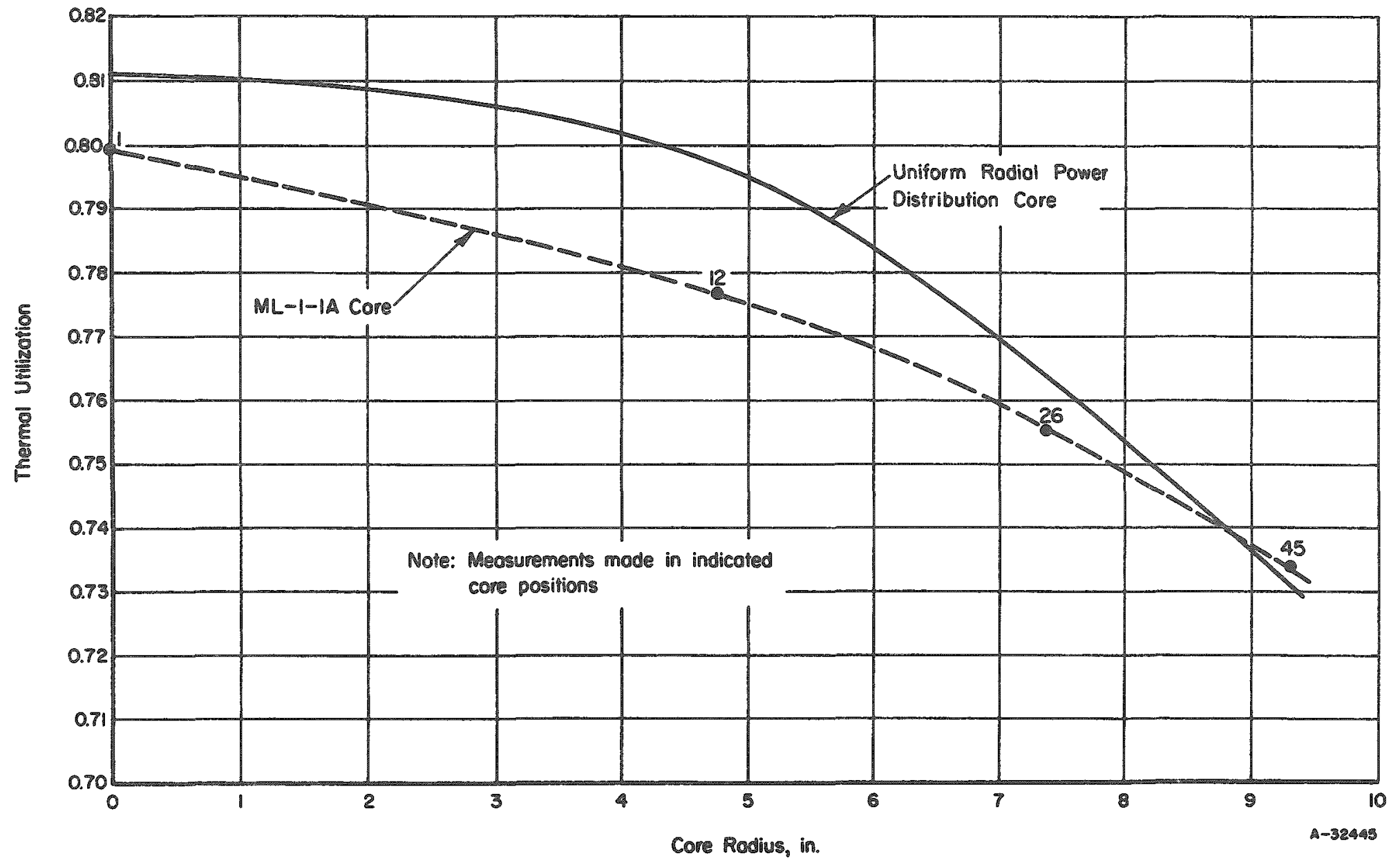

FIGURE 9. THERMAL UTILIZATION IN THE ML-1-IA CORE 
$\{1.04 \pm 0.045\} \times 10^{-4} \Delta \mathrm{k} / \mathrm{k}$ per $\mathrm{C}$ at $28.75 \mathrm{C}$, where the uncertainty represents the maximum deviation observed. In reducing reactivity data, this value was applied over a temperature range of $\sim 25$ to $30 \mathrm{C}$.

For comparison, previous temperature coefficients measured at $28.75 \mathrm{C}$ were: $0.82 \times 10^{-4}$ per $C$ for the Clean Core and $0.66 \times 10^{-4}$ per $C$ for the Lead-Reflected Core. (1)

Void Coefficients of Reactivity

During operation of the ML-1-1A power reactor, gamma heating in the structural reflectors may lead to nucleate boiling of the moderator at the moderator-reflector interface. Tests were made to estimate the reactivity effects of such voids at radial and axial interfaces using the 61 -element core.

Since the fuel region extends up to the upper-reflector surface, voids at this surface may have a noticeable reactivity effect. Since a 4-1/2-in. water reflector separates the lower grid plate from the core voids at this location would have a much smaller effect. Consequently, the void effect was measured only at the upper reflector. The voids were assumed to be homogeneously distributed over the surface of the reflector, and were simulated by making small reductions in the height of the moderator.

Over the range of water heights 66.486 to $66.888 \mathrm{in}$, the reactivity effect of changes in water heights was constant at $-0.366 \pm 0.015 \times 10^{-2} \Delta \mathrm{k} / \mathrm{k}$ per in. at $28 \mathrm{C}$. Measurements were made below 66.888 in. to eliminate meniscus problems present near the full water height, $67.211 \mathrm{in}$.

At the moderator-radial reflector interface the voids were again assumed to be homogeneously distributed. Readily available void-containing or -simulating materials (aluminum, Siyrofoam) were unsuitable because of physics and engineexing considerations. For the sake of expediency, polyethylene was used to simulate increases in hydrogen density or "negative voids". Assuming a linear relationship between small changes in hydrogen density at the interface and the associated reactivity effects, posilive void effects can be predicted by extrapolating the effects of increased hydrogen densities. Accordingly, reactivity effects of $0-, 0.060-$, and $0.120-i n$. thicknesses of polyethylene at the entire moderator-radial reflector interface were measured. The results are shown in Figure 10. A value of $-0.59 \pm 0.07 \times 10^{-2} \Delta \mathrm{k} / \mathrm{k}$ per in. $(-2.32 \pm$ $0.3 \times 10^{-4} \Delta \mathrm{k} / \mathrm{k}$ per $\mathrm{mm}$ ) of void was obtained.

The solid line is the result of a least-square analysis of the data (excluding the spurious value at $0.060 \mathrm{in}$. of polyethylene). The data were temperature corrected to $27.81 \mathrm{C}$. The measurements were repeated using the three thicknesses of polyethylene. Each thickness change required the fuel elements and upper-axial-reflector assembly to be removed from the core. This disassembly and reassembly of the core could have introduced small unknown reactivity changes and may have been responsible for some of the scatter in the data. This is, however, only conjecture, and at this time the wide scatter indicated in Figure 10 is unexplained. 


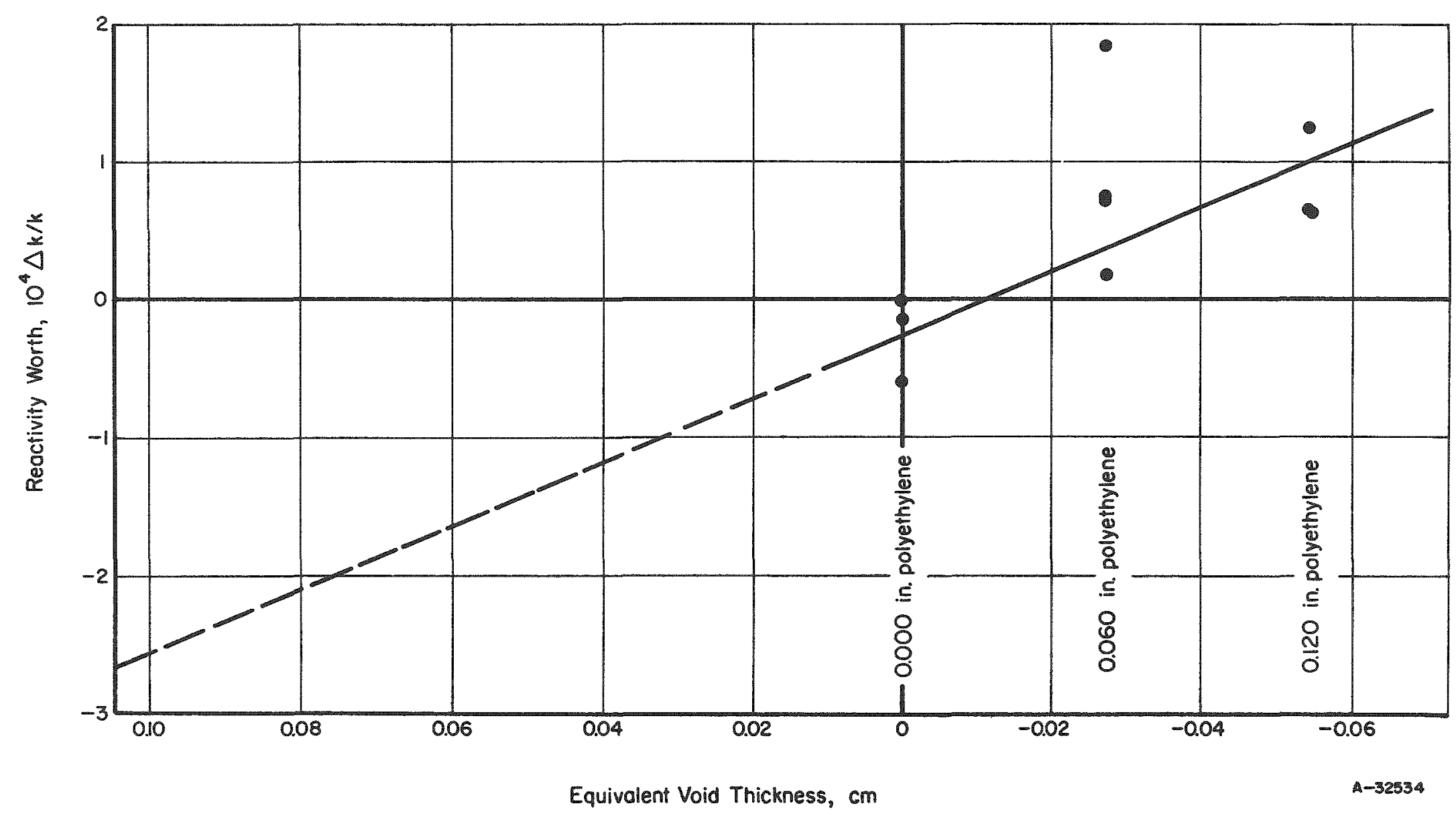

FIGURE 10. REACTIVITY WORTHS OF POLYETHYLENE SHEETS PLACED AT THE MODERATORREFLECTOR INTERFACE IN THE ML-1-1A CORE 
The power reactor will be controlled with scissorslike control blades. Measurements were made to determine the reactivity worth of a pair of the se blades as a function of their separation angle. Bare and cadmium-covered (0.020-in.-thick cadmium) blades were investigated.

The construction and locations of the mock-up blade assembly with respect to the core center lines are shown in Figure 11. The blades are stainless steel, 3 in. wide, $14 \mathrm{in.}$ long and vary in thickness from $0.625 \mathrm{in}$. to $0.125 \mathrm{in}$. When located in the core in a parallel position (zero separation angle) the blades were separated by $1 / 2$ in. The blades were centered $13 \mathrm{in}$. above the bottom of the fuel between Positions 47 and 48 parallel with the adjacent lead-reflector face (see Figure 2).

All measurements were made in a 61 -element core by noting the change in position of calibrated critical-assembly control rods required to maintain criticality for various angle separations of the blades. The results of the tests are shown in Figure 12. Because of the size of the blades the calibration of the critical-assembly control rods was checked frequently; no changes were observed throughout the tests. In general, for each configuration of the mock-up blade assembly two or more critical conditions were obtained with the calibrated critical-assembly control rods. In analyzing the data it was possible to relate a reactivity change due to a new blade configuration to those associated with all other configurations. Thus, many checks on the reactivity effect of any single mock-up control-blade configuration were available.

The length of the mock-up blades made it impossible to retract them fully into the reflector (i.e., to a 180-deg separation angle). The 180-deg separation configuration was mocked up for the cadmium-covered case by filling the cadmium sheath with an equivalent weight of steel sheet and placing this package in the $1-i n$. -wide slot in the lead. This separation angle was not duplicated for the bare blades.

The limits shown at each data point of Figure 12 indicate the upper and lower values obtained from many checks and should not be interpreted as a probable error. In the analysis of these data no corrections for wate $\mathrm{x}$-temperature variation were applied as they were small compared to the total blade worths.

\section{FUEL-ELEMENT-REPLACEMENT STUDIES}

The critical assembly was used to check reactivity of $1 \mathrm{~A}$ production fuel elements to detect gross errors in fabrication. Also, a lB-type fuel element which contained 19 $\mathrm{UO}_{2}$ fuel pins was studied to aid in predicting the performance of this element.

\section{A Fuel-Element Studies}

An attempt was made to use the critical assembly to determine the fuel and neutronabsorber (actually stainless steel equivalent) content of production $1 \mathrm{~A}$ fuel elements. 


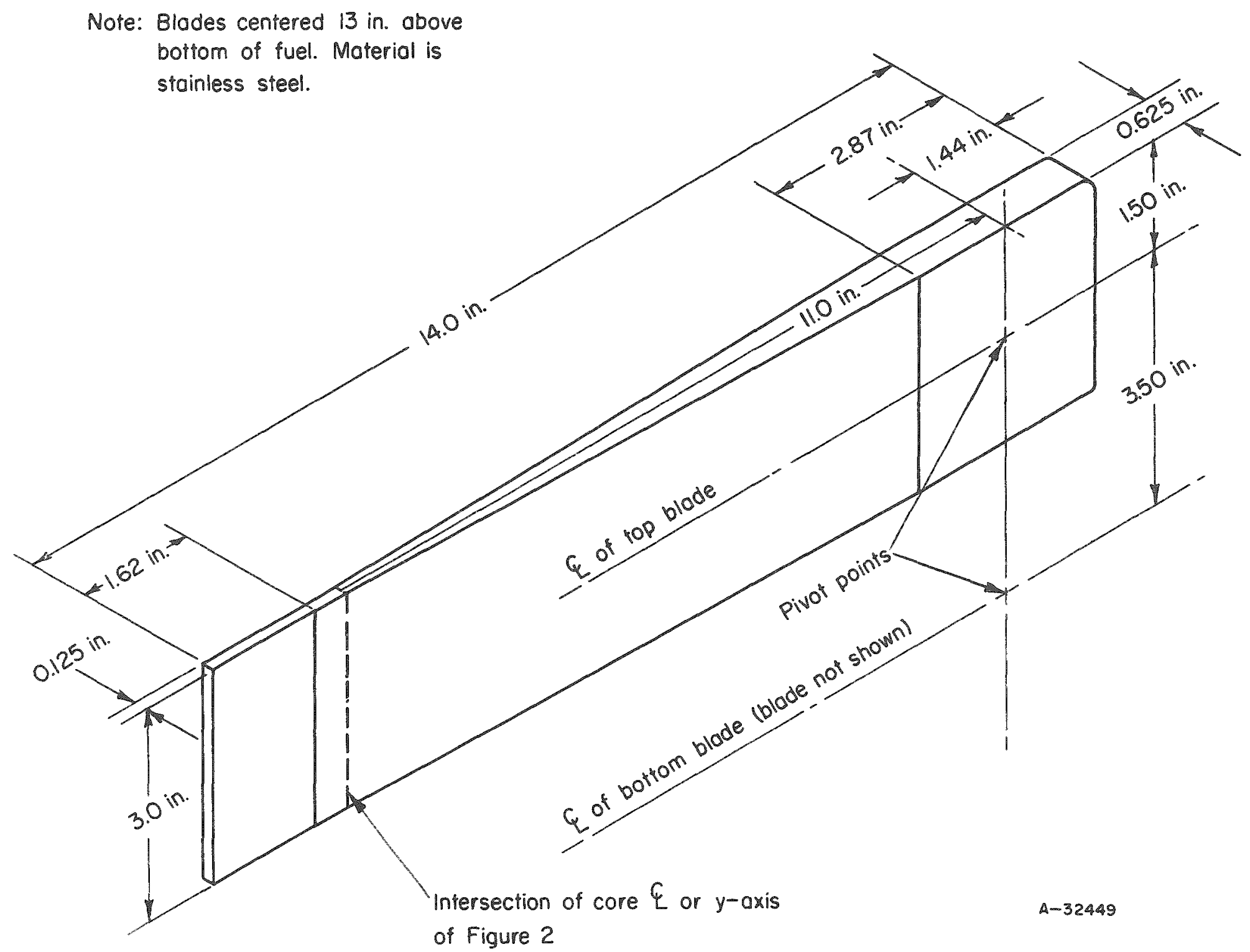




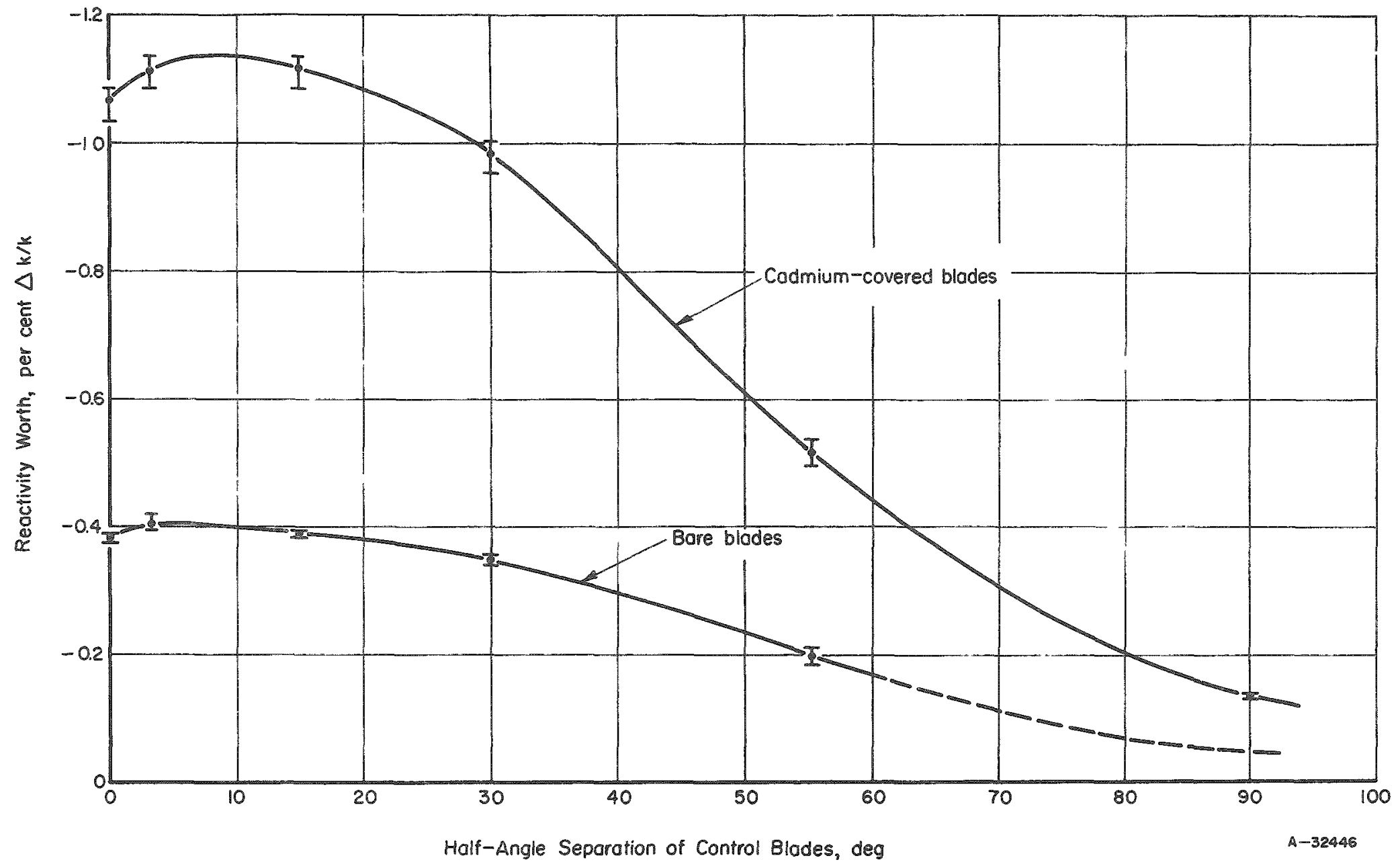

FIGURE 12. SHUTDOWr, WORTHS OF ML-1-1A CONTROI BLADES AS A FUNCTION OF TIEIR ANGULAR SEPARATION 
The power-reactor elements were shipped to Battelle by Aerojet-General Nucleonics. The production elements were longex over-all than the critical-assembly mock-up elements because of the special end fittings. For use in the experiments they were cut off so that the bottom of the fuel was aligned with the bottom of the criticalas sembly fuel.

In addition, the power-reactor elements had other significant differences from their critical assembly counterparts. These were:

(1) The fuel was in the form of a dispersion of uranium dioxide in stainless steel. The fuel-plate thickness was 45 mils, made up of 33 mils of core and 12 mils of cladding. The total estimated fuel loading of the power-reactor elements is given in Table 6. The nominal outside diameters of the fuel cylinders were 1.26. $0.94,0.75$, and $0.53 \mathrm{in}$; these value s compare respectively with the following values for the critical-assembly elements: 1.25 , $1.01,0.81$, and $0.59 \mathrm{in}$.

(2) The power-reactor element contained samarium oxide burnable poison (about $0.1 \mathrm{~g}$ in each element). The poison was in the form of a dispersion of samarium oxide in a thin steel band 6 in. wide affixed to the inside of the outer insulation-liner tube. The 6-in. samarium oxide band was 1 in. below the fuel centex line. The corresponding cadmium-band mock-up on the critical-assembly elements is $5 \mathrm{in}$. wide and is centered $1 \mathrm{in}$. above the fuel center line. This difference in position arises from the fact that the critical assembly mocks up the inverted power reactor.

(3) An outer insulation liner (zirconium) and insulation material (Thermoflex) were present on the power-reactor elements.

These were not mocked up in the critical-assembly elements.

(4) The ends of the power-reactor elements contained stainless steel structural pieces which are absent in the mock-up elements.

In conducting these studies it was assumed that for a given core position, and for approximately uniform axial distributions of fuel and steel, a linear relationship existed between the defect in fuel and/or steel weight compared with a standard critical-assembly element and the resulting reactivity change associated with the reactor. It was further assumed that similar relationships would hold with the fuel element entirely covered with a 0.010 -in. -thick cadmium sleeve.

With these assumptions, the following equation can be written:

$$
\begin{aligned}
& \Delta \rho_{\mathrm{B}}=\mathrm{a}_{\mathrm{B}} \Delta \mathrm{M}_{\mathrm{f}}+\mathrm{b}_{\mathrm{B}} \Delta \mathrm{M}_{\mathrm{sS}}, \\
& \Delta \rho_{\mathrm{C}}=\mathrm{a}_{\mathrm{C}} \Delta \mathrm{M}_{\mathrm{f}}+\mathrm{b}_{\mathrm{C}} \Delta \mathrm{M}_{\mathrm{ss}},
\end{aligned}
$$

where

$$
\begin{aligned}
\Delta \mu & =\text { change in reactivity due to defect in fuel or steel weight } \\
\Delta M_{\mathrm{f}} & =\text { fuel defect, } g
\end{aligned}
$$


$\Delta \mathrm{M}_{\mathrm{sS}}=$ steel defect, $\mathrm{g}$

$a$ and $b=$ coefficients to be determined

Subscripts B and C designate baxe and cadmium-covered elements, respectively.

The coefficients were determined by loading fuel elements with known defects of fuel and stainless steel and observing the resulting reactivity change with the eloment bare and cadmium covered. These measurements were made in Position 26 in a. $61-$ element core. Measurements were initially attempted in Position 1 , but with the 10 mil-thick cadmium sleeve covering the critical-assembly fuel element the core was not critical. The mocked-up burnable-poison band was present on the critical-assembly element only during the cadmium-covered tests.

The reactivity difference was measured by calibrated critical-assembly control rods; the data were corrected for moderator-temperature changes using a temperature coefficient of reactivity of $1.04 \times 10^{-4} \Delta \mathrm{k} / \mathrm{k}$ per $\mathrm{C}$. The corrected reactivities were found to be reproducible to within 1 to $2 \times 10^{-5} \Delta \mathrm{k} / \mathrm{k}$.

The equations resulting from these calibrations are:

$$
\begin{aligned}
\Delta M_{f} & =0.731 \times 10^{6}\left[(0.038) \Delta \mu_{B}+(0.427) \Delta \rho_{-}\right] \\
\Delta M_{S S} & =0.731 \times 10^{6}\left[(-2.34) \Delta \rho_{B}+(9.66) \Delta \rho_{C}\right]
\end{aligned}
$$

Equation (2) was applied to reactivity measurements for a critical-assembly fuel element of known composition, different from a standard element, and two special elements supplied and designated by $A G N$ as $C E-1$ and $C E-2$.

The results of these measurements are summarized in Table 6. The large apparent stainless steel defect in Elements $C E-1$ and $C E-2$ is probably due to the burnable-poison samarium oxide band which was present on these elements. The amount of cadmium used to simulate this burnable poison in the critical-assembly elements (approximately $0.4 \mathrm{~g}$ ) is actually a stronger absorbex than the samarium of the production elements (about $0.1 \mathrm{~g}$ ). (From the results of various critical conditions, without the cadmium sleeve, it has been found that the cadmium band in Position 26 represents a shutdown worth of approximately $5 \times 10^{-4} \Delta \mathrm{k} / \mathrm{k}$.) Use of cadmium bands in

\begin{tabular}{|c|c|c|c|c|c|c|}
\hline Element & $\begin{array}{c}\text { Mf Specified, } \\
\mathrm{g}\end{array}$ & $\begin{array}{c}\Delta \mathrm{M}_{\mathrm{f}} \text { specified, } \\
\mathrm{g}\end{array}$ & $\begin{array}{c}\Delta M_{f} \text { Calculated, } \\
\mathrm{g}\end{array}$ & $\begin{array}{c}\mathrm{M}_{\mathrm{SS}} \text { Actual, } \\
\mathrm{g} \\
\end{array}$ & $\begin{array}{c}\wedge M_{S S} \text { Actual, } \\
\mathrm{g} \\
\end{array}$ & $\begin{array}{c}\Lambda_{\mathrm{SS}} \text { Calculated, } \\
\mathrm{g} \\
\end{array}$ \\
\hline $\begin{array}{l}\text { ML-1-1A standard } \\
\text { element }\end{array}$ & 303.47 & 0.00 & $\infty$ & $2474(a)$ & 0.00 & -- \\
\hline $\begin{array}{l}\text { ML-1-1A with extra } \\
\text { fuel and stainless }\end{array}$ & 403.82 & 100.35 & 105.90 & 2866 & 392 & 388 \\
\hline$G C R E-C E-1(b)$ & $313.5(\mathrm{c})$ & $10.03(c)$ & -3.8 & $-\infty$ & - & 748 \\
\hline$G C R E-C E-2(b)$ & $313.0(c)$ & $9.53(\mathrm{c})$ & 2.3 & $-\infty$ & $\ldots$ & 796 \\
\hline
\end{tabular}

TABLE 6。 FUEI. AND STEEL CALIBRATION RESULTS

(a) Includes weight of pressure tube.

(b) GCRE elements were inserted in ML-1 element pressure tubes.

(c) These values represent the specified loading and are not known to be correct. 
calibrating to obtain the constants for Equation (2) would not have given correct results in terms of stainless steel, and by introducing a different absorbing material would probably have made the results more difficult to interpret.

GCRE-1B-1 $\phi$ T Fuel-Element Studies

The GCRE-1B-1 $\phi$ T fuel element was constructed of 19 uranium dioxide fuel pins clad with Inconel $\mathrm{X}$ in a triangular-pitch lattice as shown in Figure 13. The 7 central pins contained $\mathrm{UO}_{2}$ enriched to 48.53 per cent and the 12 outer pins contained $\mathrm{UO}_{2}$ enriched to 24.48 per cent. The total weight of uranium-235 in the element was $377.62 \mathrm{~g}$. The cladding consisted of an 0.030-in. -wall Inconel X tube $0.164 \mathrm{in}$. in ID by $30.985 \mathrm{in}$. long. These tubes were furnished with top and bottom plugs of Inconel $X$ and with aluminum spacers for centering the fuel in the tube.

The fuel consisted of cylindrical uranium dioxide pellets $0.250 \mathrm{in}$. long which were stacked inside the tube to give a total fuel length of $22.75 \mathrm{in}$. The fuel region was centered $17.920 \mathrm{in}$. from the top of the pin assembly. Most of the se pellets contained a central void large enough to allow a 0.004 -in. -wall-thickness aluminum tube 0.040 in. in $O D$ to be inserted into the center of the fuel pin after assembly. These aluminum tubes extended out of the fuel region to the top of the pin assembly. They acted as holders for manganese-copper wires which were used for making flux measurements.

Five of the pins were constructed such that their fuel regions were in three separable segments. One of these was a capsule $0.50 \mathrm{in}$. long that was machined to connect to the other two sections of the pin with a slip fit. The capsule was centered $2.284 \mathrm{in}$. below the center of the fuel region. The fuel in the top segment contained the aluminum tube mentioned above, but the fuel in the capsule and bottom segment did not. The remaining fourteen pins were assembled as one piece. The central aluminum tube extended the entire fuel length in these pins.

For these studies the GCRE-1B-1фT pin bundle was placed in a critical-assemblyelement insulation liner and stainless steel pressure tube; the cadmium band was removed from the insulation liner. The element was located in Position 1 in the initial 59-element configuration of Figure 4. The fuel region of the $1 \mathrm{~B}-1 \phi \mathrm{T}$ element was centered vertically at the fuel midplane of the ML-1-1A critical-assembly fuel elements. As a result, the fuel region began $7-1 / 2$ in. above the bottom reflector.

\section{Power-Distribution Measurements}

Power-distribution measurements were obtained by counting the fission-product activity in each of five fuel capsules. The capsules were $0.50-$ in. - long fuel-pin segments from Pins 1, 4, 7, 9, and 15 (see Figure 13). The measured activities of the irradiated capsules were corrected for decay, background, and activities present prior to irradiation. Relative pin-to-pin power ratios were calculated directly from these corrected activities. The se ratios are listed in Table 7 . The low value obtained for Pin 15 may be a result of the proximity of the stainless steel guide tubes for the neutron startup source (note source tubes shown in Figure 2). 


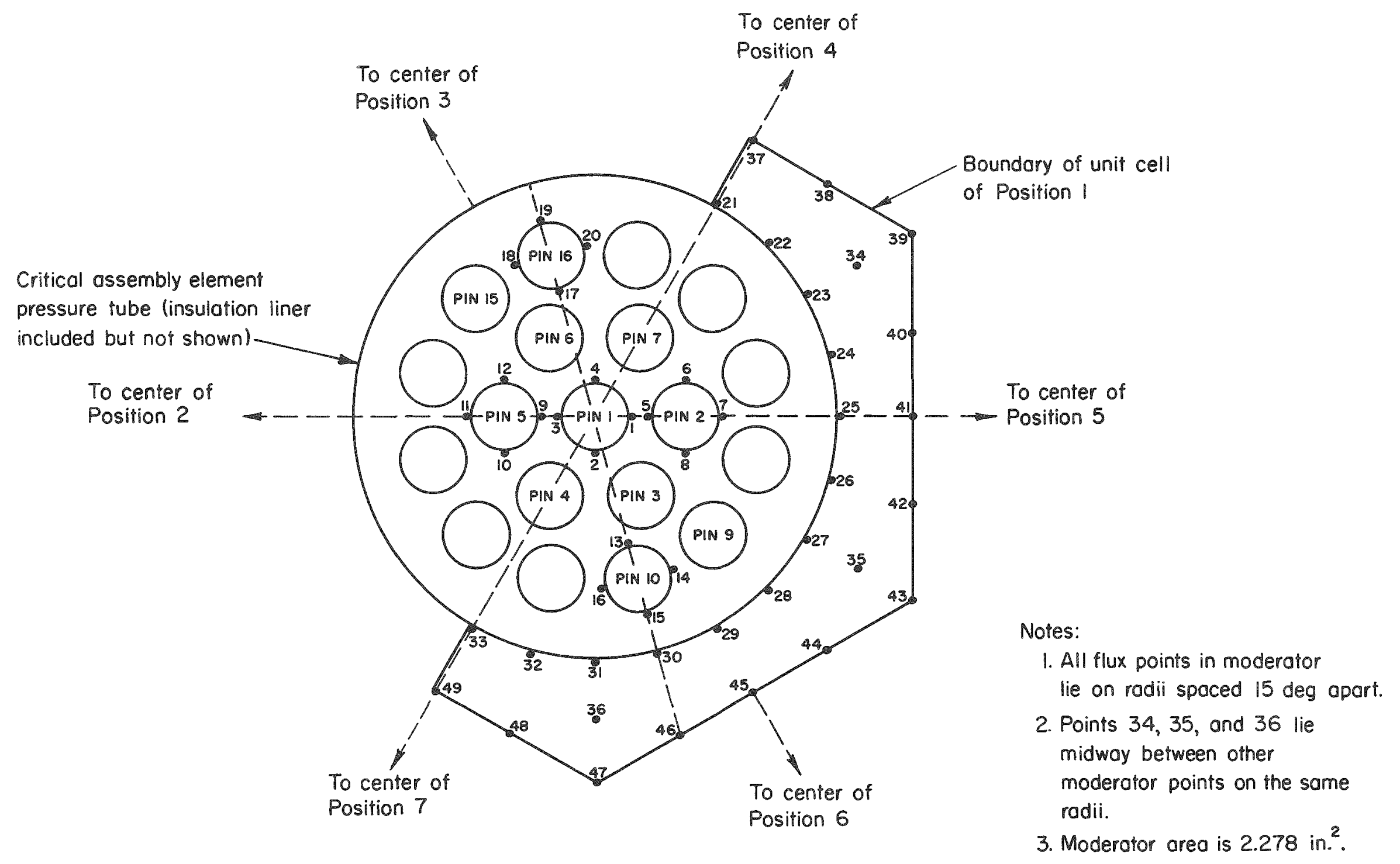

A-32455.

FIGURE 13. POSITIONS OF INTRACELL FLUX MEASUREMENTS FOR GCRE-18 FUEL ELEMENT IN POSITION OF ML-1-1A CORE 
TABLE 7. RELATIVE EUEL-PIN POWER FOR GCRE-1B-1 $1 \phi T$ FUEL ELEMENT

\begin{tabular}{rc}
\hline Pin & Power Ratio Relativa to Pin 1 \\
\hline 1 & 1.00 \\
4 & 1.10 \\
7 & 1.14 \\
9 & 1.12 \\
15 & 1.00 \\
\hline
\end{tabular}

Elux Measurements

Measurements were made in the GCRE-1B-1థT element to provide data on the detailed intracell and the axial thermal-flux distribution. In addition, data were obtained regarding possible neutron streaming between fuel pins. The information was obtained by irradiating 25-mil-diameter p-metal ( $80 \mathrm{w} / 0$ manganese-20 w/o copper) wires.

Two separate irradiations were performed in the course of the se experiments. In the first irradiation the following wires were present in and around the element:

(1) Full-length wires in the center position in all applicable fuel pins.

(2) Precut 1-in. -long wires in the moderator at a position centered $18.55 \mathrm{in}$. above the bottom of the oxide fuel. The array is shown in Figure 13.

(3) Precut 1-in. -long wires on the circumference of selected fuel pins. These were aligned with the pin axis and spaced 90 deg apart as shown on Figure 13. These wires were placed at 18.55 and 5.05 in. above the bottom of the fuel.

The axial wires in the centers of the pins were cut into $1-i n$. segments at heights corresponding to the circumferential wires, 18.55 and $5.05 \mathrm{in}$. above the bottom of the fuel, and at one additional height, $12.05 \mathrm{in}$. The normalized activity of these three wires and the wires from (2) and (3) above are given in Table 8 . They provide a complete total-activity distribution in a plane $18.55 \mathrm{in}$. above the bottom of the fuel and additional data at $5.05 \mathrm{in}$. concerning possible neutron streaming. The data from $12.05 \mathrm{in}$. above the bottom of the fuel serve as a check on the gross radial distribution of flux within the pins.

The second irradiation was performed to gather data for cadmium-covered wires so that the data at $18.55 \mathrm{in}$. could be corrected to the rmal-neutron distributions. Figure 13 shows the positions within and adjacent to the element whe re the se epicadmium wires were located. During this same run full-length bare wires were irradiated in the center of Pins 3 and 19. These latter data indicate the axial flux distribution (uncorrected for epicadmium activity). Data from the second irradiation appear in Table 8. 
TABLE 8. RELATIVE INTRACELL FLUX-DISTRIBUTION DATA FOR GCRE-1B-1\&T ELEMENT

\begin{tabular}{|c|c|c|c|c|c|c|c|c|c|c|c|c|}
\hline \multirow[b]{4}{*}{ Pin } & \multicolumn{9}{|c|}{ Radial Distribution } & \multicolumn{3}{|c|}{ Axial Distribution } \\
\hline & \multicolumn{5}{|c|}{$\begin{array}{l}\text { In Element Center at Indicated Position of Wire } \\
\text { Above Bottom of Fuel }\end{array}$} & \multirow{2}{*}{\multicolumn{4}{|c|}{$\begin{array}{c}\text { In Moderator at } 18.55 \text { In. Above } \\
\text { Bottom of Fuel }\end{array}$}} & \multirow{3}{*}{$\begin{array}{l}\text { Center Position } \\
\text { of Wire Above } \\
\text { Bottom of Fuel, } \\
\text { in. }\end{array}$} & \multirow{3}{*}{$\begin{array}{l}\text { Pin } 3_{3} \\
\text { Total }\end{array}$} & \multirow{3}{*}{$\begin{array}{l}\text { Pin } 19_{0} \\
\text { Total }\end{array}$} \\
\hline & \multirow[b]{2}{*}{ Position (a) } & \multicolumn{2}{|c|}{$18.55 \mathrm{In}$. } & \multirow{2}{*}{$\begin{array}{l}\text { 12.05 In. } \\
\text { Total }\end{array}$} & \multirow{2}{*}{$\begin{array}{c}5.05 \mathrm{In}_{0,} \\
\text { Total }\end{array}$} & & & & & & & \\
\hline & & Total & Epicadmium & & & Pin & Position & Total & Epicadmium & & & \\
\hline 1 & $\mathrm{CP}$ & 1621 & -- & 1941 & -- & 1 & 21 & 7,357 & - & 0.375 & 1640 & 3201 \\
\hline 1 & 1 & 2364 & 873 & - & 2804 & 1 & 22 & 7,490 & $-\infty$ & 1.375 & 1729 & 3103 \\
\hline 1 & 2 & 2318 & - & $\ldots$ & 2694 & 1 & 23 & 7,666 & -- & 2.375 & 1852 & 3345 \\
\hline 1 & 3 & 2274 & 926 & -- & 2711 & 1 & 24 & 7.472 & -. & 3.375 & 2040 & 3663 \\
\hline 1 & $-\infty$ & 2258 & -- & - & 2624 & 1 & 25 & 7.542 & 1377 & 4.375 & 2115 & 3821 \\
\hline 2 & $\mathrm{CP}$ & 1678 & - & 2064 & 2014 & 2 & 26 & 7,623 & $\ldots$ & 5.375 & 2257 & 3897 \\
\hline 2 & 5 & 2238 & $-\infty$ & -- & 2674 & 2 & 27 & 7,444 & -- & 6.375 & 2324 & 4076 \\
\hline 2 & 6 & 3052 & 945 & $\ldots$ & 3352 & 2 & 28 & 7,462 & - & 7.375 & 2311 & 4235 \\
\hline 2 & 7 & 3558 & 999 & - & 4021 & 2 & 29 & 7,421 & -- & 8.375 & 2384 & 4241 \\
\hline 2 & 8 & 3282 & 943 & -- & 3748 & 2 & 30 & 7,533 & $-\infty$ & 9.375 & 2305 & 4191 \\
\hline 3 & $\mathrm{CP}$ & 1708 & $=$ & 2067 & 2034 & 3 & 31 & 7,545 & 1328 & 10.375 & 2346 & 3984 \\
\hline 4 & $\mathrm{CP}$ & 1706 & -- & 2072 & -. & 4 & 32 & 7,401 & - & 11.375 & 2315 & 3899 \\
\hline 5 & $\mathrm{CP}$ & 1635 & -- & 2026 & 1958 & 5 & 33 & 7,044 & $-\infty$ & 12.375 & 2244 & 3922 \\
\hline 5 & 9 & 2427 & $=-$ & $\ldots$ & - & 5 & 34 & 11,726 & $-\infty$ & 13.375 & 2185 & 3820 \\
\hline 5 & 10 & 3135 & 383 & $-\infty$ & $-\infty$ & 5 & 35 & 11,909 & $-\infty$ & 14.375 & 2228 & 3798 \\
\hline 5 & 11 & 3147 & 1016 & $\ldots$ & $-\infty$ & 5 & 36 & 10,974 & -. & 15.375 & 2109 & 3699 \\
\hline 5 & 12 & 2489 & 962 & 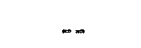 & -- & 5 & 37 & 9.860 & 1369 & 16.375 & 2039 & 3507 \\
\hline 6 & $\mathrm{CP}$ & 1676 & - & 2033 & 1992 & 6 & 38 & 11,834 & - & 17.375 & 1846 & 3102 \\
\hline 7 & $\mathrm{CP}$ & 1689 & - & - & $\ldots$ & 7 & 39 & 12,496 & 1331 & 18.375 & 1493 & 2850 \\
\hline 8 & $\mathrm{CP}$ & 3113 & - & 3704 & 3588 & 8 & 40 & 11,208 & $-\infty$ & 19.375 & 1550 & 3013 \\
\hline 9 & $\mathrm{CP}$ & 3026 & $-\infty$ & 3606 & - & 9 & 41 & 10,817 & 1363 & 20.375 & 1595 & 2979 \\
\hline 10 & $\mathrm{CP}$ & 3267 & -- & 3914 & 3869 & 10 & 42 & 11,968 & - & 21.375 & 1559 & 2840 \\
\hline 10 & 13 & 3221 & 1002 & $\ldots$ & -- & 10 & 43 & 12,838 & 1400 & 22.375 & 1535 & 2869 \\
\hline 10 & 14 & 5071 & 1139 & -. & $\ldots$ & 10 & 44 & 11,127 & - & 23.375 & 4597 & 5119 \\
\hline 10 & 15 & 6218 & 1091 & -- & - & 10 & 45 & 10,330 & 1807 & 24.375 & 2989 & 4636 \\
\hline 10 & 16 & 4369 & $-\infty$ & -- & $m$ & 10 & 46 & 10,875 & -- & 25.375 & 2637 & 2892 \\
\hline 11 & $\mathrm{CP}$ & 2968 & $=$ & 3628 & 3559 & 11 & 47 & 11,967 & 1267 & 26.375 & 1221 & 1152 \\
\hline 12 & $\mathrm{CP}$ & 3039 & - & 3653 & 3581 & 12 & 48 & 10,968 & $-\infty$ & 27.375 & 523 & 533 \\
\hline 13 & $\mathrm{CP}$ & 2968 & -- & 3589 & 3466 & 13 & 49 & 10,178 & 1298 & 28.375 & 243 & 239 \\
\hline 14 & $\mathrm{CP}$ & 2818 & $-\infty$ & 3466 & 3486 & 14 & & & & 29.375 & 114 & 89 \\
\hline 15 & $\mathrm{CP}$ & 2850 & -- & 3313 & $=$ & & & & & & & \\
\hline 16 & $\mathrm{CP}$ & 2878 & - & 3468 & 3526 & & & & & & & \\
\hline 16 & 17 & 3240 & 994 & $=$ & 4041 & & & & & & & \\
\hline 16 & 18 & 3610 & 1135 & - & 6738 & & & & & & & \\
\hline 16 & 19 & 5742 & 1205 & - & 6281 & & & & & & & \\
\hline 16 & 20 & 5340 & - & - & 3959 & & & & & & & \\
\hline 17 & $\mathrm{CP}$ & 3008 & -- & 3593 & 3523 & & & & & & & \\
\hline 18 & $C P$ & 3087 & -- & 3595 & 3690 & & & & & & & \\
\hline 19 & $\mathrm{CP}$ & 3162 & -- & 3624 & 3759 & & & & & & & \\
\hline
\end{tabular}




\section{DISCUSSION}

\section{Critical Configuration}

The ML-1-1A critical-assembly core structure differed from previously studied cores in the construction and location of the radial and upper axial reflectors. The radial reflector was a regular hexagon, $4 \mathrm{in}$. thick and $28 \mathrm{in.}$ long, formed of refined lead. The 3-1/2-in.-thick upper axial reflector was made of steel. The top of the lead was coplanar with the top of the fuel and the full-water-height position.

Except for pressure tubes, the fuel elements were identical to the previously used GCRE-1 critical-assembly elements. A stainless tube replaced a slightly larger aluminum pressure tube.

The ML-1-1A core was critical with 59 elements containing 17,906.71 g of uranium-235, and had an excess reactivity of $0.381 \times 10^{-2} \Delta \mathrm{k} / \mathrm{k}$ at a moderator temperature of $24.91 \mathrm{C}$.

Results of Flux and Power Measurements

Flux and power measurements show increased uniformity of the radial distributions when compared with the previously studied URPD coxe. The ratio of maximum element power to core-averaged power was approximately 1.09. Percentages of total element power generated in each fuel cylinder were measured. The data indicated a slight variation of these percentages with radius; the percentage generated in the outer fuel cylinder increased slightly while that in the inner fuel cylinder decreased slightly with increased radius.

The relative the rmal-flux measurements indicate a ratio of maximum to coreaveraged flux of approximately 1.10. Detailed intracell measurements were made to aid in thermal-utilization calculations. Results are shown in Table 9.

TABLE 9. THERMAL UTILIZATION(a) AS A FUNCTION OF CORE POSITION

\begin{tabular}{lcccc}
\hline & Position 1 & Position 12 & Position 26 & Position 45 \\
$\begin{array}{l}\text { Calculated Values of } \\
\text { Thermal Utilization }\end{array}$ & 0.799 & 0.776 & 0.755 & 0.734 \\
\hline
\end{tabular}

(a) Note text for interpretation of data leading to tabulated values. See figure 2 for element positions.

Reactivity Worth of ML-1-1A Mock-Up Control-Blade Assembly

The reactivity worth as a function of blade-separation angle was measured for a mock-up of the ML-1-1A scissorlike control blades. Both bare and cadmium-covered steel blades were investigated. A maximum value of approximately $-1.14 \times 10^{-2} \Delta \mathrm{k} / \mathrm{k}$ at an 18-deg separation was obtained for cadmium-covered blades. The maximum value for the bare blades was measured as $-0.41 \times 10^{-2} \Delta \mathrm{k} / \mathrm{k}$ at a $10-$ deg separation. The 
measurements were made in a 61-element core containing $18,510.96 \mathrm{~g}$ of uranium-235 and having an excess reactivity of $1.300 \times 10^{-2} \Delta \mathrm{k} / \mathrm{k}$ at $23.19 \mathrm{C}$.

\section{Void Coefficient of Reactivity}

Void coefficients of reactivity were measured at the radial and upper axial reflector-moderator interfaces. At the upper axial reflector, a void was introduced by lowering the water height. A reactivity effect of $-0.366 \pm 0.015 \times 10^{-2} \Delta \mathrm{k} / \mathrm{k}$ pe $x$ in. at $28 \mathrm{C}$ was measured.

At the moderator-radial reflector interface polyethylene was used to determine void coefficients. As a result of the measurements an approximate reactivity effect of $-0.59 \pm 0.07 \times 10^{-2} \Delta \mathrm{k} / \mathrm{k}$ per in. is predicted for a uniform void at the moderatorradial reflector interface. The methods and assumption used in measuring this value are discussed in the text.

\section{A Fuel-Element Studies}

The ML-1-1A critical as sembly was used in an attempt to detect gross errors in the fabrication of 1 A production fuel elements. The calibrated reactivity effects of known defects in fuel and stainless steel loadings in a standard critical-assembly fuel element were used to calibrate two $1 \mathrm{~A}$ production fuel elements, CE-1 and CE-2. The results predict that the production elements tested contained roughly the same fuel as the critical-assembly element and an additional $772 \mathrm{~g}$ of stainless steel equivalent on the average. The se results are tabulated below.

TABLE 10. 1A PRODUCT ION-ELEMENT CALIBRATION

\begin{tabular}{|c|c|c|c|c|}
\hline Element & $\Delta M_{f}^{(2)}$ Specified, $\delta$ & $\Delta M_{f}{ }^{(a)}$ Measured, $g$ & $\Delta \mathrm{M}_{\mathrm{ss}}{ }^{(\mathrm{a})}$ Specified, $\mathrm{g}$ & $M_{\mathrm{Ss}}{ }^{(\mathrm{a})}$ Measured, $g$ \\
\hline$C E-1$ & 10.03 & -3.8 & $-\infty$ & 748 \\
\hline CE-2 & 9.53 & 2.3 & $-\infty$ & $79 \hat{0}$ \\
\hline
\end{tabular}

(a) Difference in mass of fuel (f) and stainless steel equivalent (ss) with respect to crirical-assembly fuel element.

\section{B Fuel-Element Studies}

Power and neutron-flux distributions were measured in a 19-pin $1 \mathrm{~B}$ fuel element in the center position of the ML-1-1A core. Pin-to-pin power ratios indicate a fairly uniform radial distribution increasing from the center pin to a value of about between 1.10 and 1.14 in the second ring of 6 pins and showing a slight decrease to a value between 1.12 to 1.00 of the central value in the outer 12 pins. The the rmal flux behaved similarly. Data were obtained which may be used to evaluate the thermal utilization for this fuel element. 


\section{REFERENCES}

(1) Dingee, D. A., Ballowe, W. C., Klingensmith, R. W., Egen, R. A., Jankowski. F. J., and Chastain, J. W., "GCRE Critical-Assembly Studies", BMI-1288 (September 10, 1958).

(2) Dingee, D. A., Ballowe, W. C., Egen, R. A., Jankowski, F. J., and Chastain, J. W., "Further Studies With the GCRE Critical Assembly", BMI-1306 (December 29, 1958). Confidential.

RAE:WSH:DAD:JWC/mmk 